\title{
Linear dynamic harmonic regression ${ }^{2}$
}

\author{
Marcos Bujosa $^{\mathrm{a}, *}$, Antonio García-Ferrer ${ }^{\mathrm{b}}$, Peter C. Young ${ }^{\mathrm{c}, \mathrm{d}}$ \\ ${ }^{a}$ Dpto. de Fundamentos del Análisis Económico II, Universidad Complutense de Madrid, Somosaguas, 28223 Madrid, Spain \\ ${ }^{\mathrm{b}}$ Dpto. de Análisis Económico: Economía Cuantitativa, Universidad Autónoma de Madrid, Cantoblanco, 28034 Madrid, Spain \\ ${ }^{\mathrm{c}}$ Centre for Research on Environmental Systems and Statistics, Lancaster University, Lancaster LA1 4YQ, UK \\ ${ }^{\mathrm{d}}$ Integrated Catchment Assessment and Management Centre, Australian National University, Australia
}

Available online 26 July 2007

\begin{abstract}
Among the alternative unobserved components formulations within the stochastic state space setting, the dynamic harmonic regression (DHR) model has proven to be particularly useful for adaptive seasonal adjustment, signal extraction, forecasting and back-casting of time series. First, it is shown how to obtain AutoRegressive moving average (ARMA) representations for the DHR components under a generalized random walk setting for the associated stochastic parameters; a setting that includes several wellknown random walk models as special cases. Later, these theoretical results are used to derive an alternative algorithm, based on optimization in the frequency domain, for the identification and estimation of DHR models. The main advantages of this algorithm are linearity, fast computational speed, avoidance of some numerical issues, and automatic identification of the DHR model. The signal extraction performance of the algorithm is evaluated using empirical applications and comprehensive Monte Carlo simulation analysis.
\end{abstract}

(C) 2007 Elsevier B.V. All rights reserved.

Keywords: Dynamic harmonic regression; Unobserved component models; Spectral fitting; Ordinary least squares

\section{Introduction}

During the last two decades, much of the literature on signal extraction has been based on a 'model-based' approach, where a stochastic model is formulated and used to design algorithms that extract important features from the data. Three directions have emerged: (1) one, termed the ARIMA-model based or "reduced" form model (see Box et al., 1978; Hillmer and Tiao, 1982; Burman, 1980; Gomez and Maravall, 1996a); (2) a second one, termed optimal regularization (see Akaike, 1980; Jakeman and Young, 1984; Young, 1991); and (3) a third one that begins by directly specifying the model for the components within an stochastic state space (SS) setting. This last SS formulation was originated in the 1960s in the control engineering area and has been adopted by the statistical literature in recent years (see Harvey, 1989; West and Harrison, 1989; Young et al., 1988; Young, 1994). In spite of some differences in their specifications, the models in these approaches are closely related. The relationship and, in some cases, the exact equivalence of these methods is discussed in Young and Pedregal (1999) within the context of optimal filter theory.

\footnotetext{
The GNU/Octave (and MATLAB) toolbox can be freely downloaded from http://www.ucm.es/info/ecocuan/mbb/ldhr/.

* Corresponding author. Tel.: +34 913942384; fax: +34913942613.

E-mail addresses: marcos.bujosa@ccee.ucm.es (M. Bujosa), antonio.garcia@uam.es (A. García-Ferrer), p.young@lancaster.ac.uk (P.C. Young).
} 
The dynamic harmonic regression (DHR) model developed by Young and co-workers in the 1980s (see Young et al., 1999) and incorporated in the CAPTAIN Toolbox for Matlab, ${ }^{1}$ belongs to the unobserved components (UC) type and is formulated within the SS. Here, the model is represented in the observation equation and the associated stochastic parameters, that characterize this model, are defined by the stochastic state equations. The DHR model is based on a spectral approach, under the hypothesis that the observed time series is periodic or quasi-periodic and can be decomposed into spectral components: e.g. at a fundamental frequency and its associated sub-harmonics. This is an appropriate hypothesis if a spectrum of the observed time series (e.g. the periodogram or AutoRegressive spectrum) reveals spectral peaks that relate to these components (Pollock, 2006). By 'quasi-periodic', we mean here that the amplitude and the phase of the periodicity may vary over time.

Basically, the method attempts to: (1) identify the spectral peaks in an empirical spectrum of the time series data; (2) assign a DHR component to each spectral peak; (3) optimize the hyper-parameters that control the shape of the modelled spectral peaks, so that the pseudo-spectrum of the DHR model fits the empirical spectrum; and (4) estimate the DHR components using the Kalman filter and the fixed interval smoothing (FIS) algorithms (Pollock, 2003).

In the univariate case, the DHR model can be written as a UC model of the form:

$$
y_{t}=T_{t}+S_{t}+e_{t} ; \quad t=0,1,2, \ldots,
$$

where $y_{t}$ is the observed time series; $T_{t}$ is the trend or low-frequency component; $S_{t}$ is the periodic or quasi-periodic component which may represent seasonal behaviour; and $e_{t}$ is an irregular component defined as a normally distributed Gaussian sequence with zero mean value and variance $\sigma_{e}^{2},\left(\left\{e_{t}\right\} \sim\right.$ w.n. $\left.N\left(0, \sigma_{e}^{2}\right)\right)$.

The DHR algorithm, described below, has been used extensively for many years, in both the micro-CAPTAIN DOS program and the CAPTAIN Toolbox for Matlab. As a time series and forecasting algorithm it has been used in different areas of research, such as business cycle analysis (García-Ferrer and Queralt, 1998), numerous environmental applications (e.g. Young, 1999; Young and Pedregal, 1999, etc), industrial turning point predictions (García-Ferrer and Bujosa-Brun, 2000), and forecasting economic sectorial demand (García-Ferrer et al., 1997), etc. Additionally, the DHR model is a powerful signal extraction alternative that can compete well with well-known techniques (García-Ferrer and Bujosa-Brun, 2000) such as the ARIMA-based models like SEATS/TRAMO (Gomez and Maravall, 1996b; Maravall, 1993) and the structural model used in the STAMP program (Koopmans et al., 1995).

In this paper, we propose an alternative algorithm for the identification and estimation of DHR models. The article is organized as follows. Section 2 outlines the basic results of the former DHR algorithm. Section 3 shows that each DHR component has a possibly non-stationary AutoRegressive moving average ARMA representation and presents two propositions are shown in Appendix A.4. In Section 4 the new LDHR algorithm is derived. In Section 5 a simultaneous identification and estimation algorithm is proposed. In Section 6 we present some simulation results regarding alternative identification/estimation cases. Finally, in Section 7 we discuss the implications of the results for existing and future work.

\section{The former DHR algorithm}

In the DHR model $T_{t}$ and $S_{t}$ consist of a number of DHR components, $s_{t}^{p_{j}}$, with the general form

$$
s_{t}^{p_{j}}=a_{j_{t}} \cos \left(\omega_{j} t\right)+b_{j_{t}} \sin \left(\omega_{j} t\right),
$$

where $p_{j}$ and $\omega_{j}=1 / p_{j}$ are, respectively, the period and the frequency associated with the $j$ th DHR component; $T_{t}$ is the zero frequency term $\left(T_{t} \equiv s_{t}^{\infty}=a_{0 t}\right)$, while the periodic component is $S_{t}=\sum_{j=1}^{R} s_{t}^{p_{j}}$, where $j=1, \ldots, R$ are the associated periodic frequencies. Hence, the complete DHR model can be written in the form:

$$
y_{t}^{d h r}=\sum_{j=0}^{R} s_{t}^{p_{j}}+e_{t}=\sum_{j=0}^{R}\left\{a_{j_{t}} \cos \left(\omega_{j} t\right)+b_{j_{t}} \sin \left(\omega_{j} t\right)\right\}+e_{t} .
$$

The trigonometric terms that define each DHR component $s_{t}^{p_{j}}$ are modulated by $a_{j_{t}}$ and $b_{j_{t}}$ which are assumed to be stochastic time variable parameters that follow a generalized random walk (GRW) process (see e.g. Young et al., 1999,

\footnotetext{
${ }^{1}$ Downloadable from http://www.es.lancs.ac.uk/cres/captain/.
} 
and the prior references therein): this includes the random walk (RW), integrated random walk (IRW) and smoothed random walk (SRW) as special examples. Here, however, we consider a modified interpretation of the GRW model and where the variations can be characterized as an $\mathrm{AR}(2)$ stochastic process, normally with one or two unit roots

$$
\left.\begin{array}{l}
\left(1-\alpha_{j} L\right)\left(1-\beta_{j} L\right) a_{j_{t}}=\xi_{j_{t}} \\
\left(1-\alpha_{j} L\right)\left(1-\beta_{j} L\right) b_{j_{t}}=v_{j_{t}}
\end{array}\right\} \quad \text { where }\left[\begin{array}{c}
\xi_{j} \\
v_{j}
\end{array}\right]_{t}=\eta_{j_{t}} \sim \text { w.n. } N\left(\mathbf{0}, \sigma_{j}^{2} \mathbf{I}\right),
$$

where $\eta_{j_{t}}$ is uncorrelated with $\eta_{i \tau}$ for $i \neq j$ and any $t, \tau$; and $0 \leqslant \alpha_{j}, \beta_{j} \leqslant 1$. In this manner, therefore, non-stationarity is allowed in the various components. It is clear that the DHR model can be considered as a straightforward extension of the classical harmonic regression model, in which the gain and phase of the harmonic components can vary as a result of estimated temporal changes in the parameters $a_{j_{t}}$ and $b_{j_{t}}$. The main difference between the DHR model and related techniques, such as Harvey's structural model (Harvey, 1989) lies in the formulation of the UC model for the periodic components and the method of optimizing the hyper-parameters discussed below.

The method for optimizing the hyper-parameters of the model (i.e., the variances $\boldsymbol{\sigma}_{d h r}^{2}=\left[\sigma_{0}^{2}, \sigma_{1}^{2}, \ldots, \sigma_{R}^{2}\right]^{\prime}$ of the processes $\xi_{j}, j=0, \ldots, R$, and the variance $\sigma_{e}^{2}$ of the irregular component) was formulated by Young et al. (1999) in the frequency domain, and is based upon expressions for the pseudo-spectrum of the full DHR model:

$$
f_{d h r}\left(\omega, \boldsymbol{\sigma}^{2}\right)=\sigma_{e}^{2}+\sum_{j=0}^{R} \sigma_{j}^{2} S_{j}(\omega), \quad \boldsymbol{\sigma}^{2}=\left[\sigma_{e}^{2}, \boldsymbol{\sigma}_{d h r}^{2}\right]^{\prime},
$$

where $\sigma_{j}^{2} S_{j}(\omega)$ are the pseudo-spectra of the DHR components $s^{p_{j}}$, and $\sigma_{e}^{2}$ is the variance of the irregular component (Young et al., 1999, p. 377).

A simple manipulation of (4) allows us to write

$$
f_{d h r}\left(\omega,\left[\sigma_{e}^{2}, \mathbf{N V R}\right]\right)=\sigma_{e}^{2} \cdot\left[1+\sum_{j=0}^{R} N V R_{j} \cdot S_{j}(\omega)\right]
$$

where NVR is a vector of noise-variance ratios (sometimes termed signal/noise ratios) with elements $N V R_{j}=\sigma_{j}^{2} / \sigma_{e}^{2}, \quad j=$ $0,1, \ldots, R$. Young et al. (1999) then propose one final simplification, using the residual variance $\widehat{\sigma}^{2}$ from a fitted AutoRegressive (AR) model, as an estimate of $\sigma_{e}^{2}$. They describe the complete DHR algorithm in the following four steps:

(1) Estimate an $\operatorname{AR}(n)$ spectrum $f_{y}(\omega)$ of the observed time series and use its associated residual variance $\widehat{\sigma}^{2}$ as the estimate of $\sigma_{e}^{2}$. The AR order is usually identified by the Akaike information criterion (AIC).

(2) Find the linear least squares estimate of the NVR hyper-parameter vector which minimizes the linear least squares function

$$
J\left(f_{y}, f_{d h r}\right)=\sum_{k=1}^{m}\left[f_{y}\left(\omega_{k}\right)-f_{d h r}\left(\omega_{k},\left[\widehat{\sigma}^{2}, \mathbf{N V R}\right]\right)\right]^{2},
$$

where $\omega_{k} \in[0 \pi]$ are the $m$ points where the pseudo-spectra $f_{y}$ and $f_{d h r}$ are evaluated.

(3) Find the non-linear least squares estimate of the NVR hyper-parameter vector which minimizes the non-linear least squares function

$$
J_{L}\left(f_{y}, f_{d h r}\right)=\sum_{k=1}^{m}\left[\log f_{y}\left(\omega_{k}\right)-\log f_{d h r}\left(\omega_{k},\left[\hat{\sigma}^{2}, \mathbf{N V R}\right]\right)\right]^{2}
$$

using the result from step 2 to define the initial conditions.

(4) Use the NVR estimates from step 3 to obtain the recursive forward pass (Kalman filter) and backward pass (FIS algorithm) smoothed estimates of the DHR components. 


\section{A fundamental result on DHR components}

In this section, it is shown that each DHR component has a possibly non-stationary ARMA representation (from now on we will slightly abuse the notation and refer to an ARMA process even when it has autoregressive unit modulus roots). It is important to remark that this link between ARMA models and DHR component has a major role in the development of a new linear DHR algorithm, and it also suggests an automatic identification procedure for DHR models.

From (1) and (3), the trend follows an $\mathrm{AR}(2)$ whose pseudo-spectrum is

$$
f_{T}(\omega)=\frac{\sigma_{\xi_{0}}^{2}}{\left(1-2 \alpha_{0}+\alpha_{0}^{2}\right)\left(1-2 \beta_{0}+\beta_{0}^{2}\right)},
$$

and the Nyquist component also follows an AR(2) model with pseudo-spectrum:

$$
f_{s^{2}}(\omega)=\frac{\sigma_{\xi_{R}}^{2}}{\left(1+2 \alpha_{R}+\alpha_{R}^{2}\right)\left(1+2 \beta_{R}+\beta_{R}^{2}\right)} .
$$

For the case of the remaining cyclical and seasonal components, two propositions are shown in Appendix A.4. The first one states that, for each cyclical and seasonal component $s^{p_{j}}$, there is a sequence of real numbers, $\Lambda_{s} p_{j}$, such that its extended Fourier transform $\mathscr{F} \mathscr{E}$ (i.e., the fraction of the Fourier transform of the numerator and the Fourier transform of the denominator) is the pseudo-spectrum of $s^{p_{j}}$. The second one shows the existence of an ARMA model whose pseudo-covariance generating function is $\Lambda_{s} p_{j}$. Consequently, the pseudo-spectrum of that ARMA model is the pseudo-spectrum of $s^{p_{j}}$. The pseudo-spectra for these components are given, due to the modulation property (see Bujosa, 2000), by

$$
f_{s} p_{j}(\omega)=\mathscr{F} \mathscr{E}\left(\Lambda_{s} p_{j}(z)\right)=\frac{1}{2}\left[f_{a}\left(\omega-\omega_{j}\right)+f_{a}\left(\omega+\omega_{j}\right)\right], \quad \omega_{j} \in(0, \pi) .
$$

It follows that these pseudo-spectra $f_{s} p_{j}(\omega), 0<j<R$, can be stated as

$$
\begin{aligned}
f_{s} p_{j}(\omega)= & \frac{\sigma_{j}^{2} / 2}{\left(1+\alpha_{j}^{2}-2 \alpha_{j} \cos \left(\omega-\omega_{j}\right)\right)\left(1+\beta_{j}^{2}-2 \beta_{j} \cos \left(\omega-\omega_{j}\right)\right)} \\
& +\frac{\sigma_{j}^{2} / 2}{\left(1+\alpha_{j}^{2}-2 \alpha_{j} \cos \left(\omega+\omega_{j}\right)\right)\left(1+\beta_{j}^{2}-2 \beta_{j} \cos \left(\omega+\omega_{j}\right)\right)} .
\end{aligned}
$$

Finally, the spectrum for the irregular component is $\sigma_{e}^{2}$.

The important consequence of the previous results is that we can write the DHR model $y_{t}^{d h r}=e_{t}+\sum_{j=0}^{R} s_{t}^{p_{j}}$, as a white noise process $\left\{e_{t}\right\}$ plus a sum of $(R+1)$ ARMA models. The specific ARMA model for each DHR component depends on the type of GRW process followed by the $a_{j}$ and $b_{j}$ parameters. In all cases, however, the modulus of the AR roots are always $\alpha_{j}^{-1}$ and $\beta_{j}^{-1}$ (see Eq. (3)). Table 1 shows the corresponding ARMA models for the DHR components under different AR or GRW specifications, i.e., RW, IRW or SRW. Finally, Table 2 shows the alternative ARMA specifications for the different components: trend, cyclical and periodic, as well as the Nyquist component.

Table 1

Summary of ARMA models of the components

\begin{tabular}{lll}
\hline Component & AR and RW $\alpha_{j}=0 ; 0<\beta_{j} \leqslant 1$ & SRW and IRW $0 \leqslant \alpha_{j} \leqslant 1 ; \beta_{j}=1$ \\
\hline Trend $T$ & $\operatorname{AR}(1)$ & $\operatorname{AR}(2)$ \\
Nyquist $s^{2}$ & $\operatorname{AR}(1)$ & $\operatorname{AR}(2)$ \\
Seasonal $s^{4}\left(\omega_{j}=\pi / 2\right)$ & $\operatorname{AR}(2)$ & $\operatorname{ARMA}(4,2)$ \\
Cyclical or seasonal $s^{p_{j}}\left(p_{j} \neq 4\right)$ & $\operatorname{ARMA}(2,1)$ & $\operatorname{ARMA}(4,2)$ \\
\hline
\end{tabular}


Table 2

ARMA specification for the DHR components

\begin{tabular}{|c|c|c|c|}
\hline AR or GRW model & Trend $\left[T_{t}\right]\left(\omega_{0}=0\right)$ & Cyclical and seasonal components ${ }^{\mathrm{a}}\left[s_{t}^{p_{j}}\right]\left(0<\omega_{j}<\pi\right)$ & Nyquist component $\left[s_{t}^{2}\right]\left(\omega_{j}=\pi\right)$ \\
\hline General model $(0 \leqslant \alpha, \beta \leqslant 1)$ & $\left(1-\alpha_{0} L\right)\left(1-\beta_{0} L\right) T_{t}=\xi_{0 t-1}$ & $\left(\phi_{j}^{\alpha}(L) * \phi_{j}^{\beta}(L)\right) s_{t}^{p_{j}}=\left(\sqrt{\frac{\alpha_{j} \beta_{j} \cos \left(2 \omega_{j}\right)}{\gamma_{j}^{*} \eta_{j}^{*}}}\right)\left(1-\theta_{j}^{1} L-\theta_{j}^{2} L^{2}\right) \xi_{j_{t-1}}$ & $\left(1-\alpha_{R} L\right)\left(1-\beta_{R} L\right) s_{t}^{2}=\xi_{R t-1}$ \\
\hline Random walk (RW) $(\alpha=0, \beta=1)$ & $(1-L) T_{t}=\xi_{0 t-1}$ & $\left(1-2 \cos \left(\omega_{j}\right) L+L^{2}\right) s_{t}^{p_{j}}=\sqrt{1+\sin \left(\omega_{j}\right)}\left(1-\frac{\cos \left(\omega_{j}\right)}{1+\sin \left(\omega_{j}\right)} L\right) \xi_{j_{t-1}}$ & $(1+L) s_{t}^{2}=\xi_{R t-1}$ \\
\hline Smoothed random walk (SRW) $(0<\alpha<1, \beta=1)$ & $\left(1-\alpha_{0} L\right)(1-L) T_{t}=\xi_{0 t-1}$ & $\left(\phi_{j}^{\alpha}(L) * \phi_{j}^{\beta}(L)\right) s_{t}^{p_{j}}=\left(\sqrt{\frac{\alpha_{j} \cos \left(2 \omega_{j}\right)}{\gamma_{j}^{*} \eta_{j}^{*}}}\right)\left(1-\theta_{j}^{1} L-\theta_{j}^{2} L^{2}\right) \xi_{j_{t-1}}$ & $\left(1+\alpha_{R} L\right)(1+L) s_{t}^{2}=\xi_{R t-1}$ \\
\hline Integrated random walk (IRW) $(\alpha=\beta=1)$ & $(1-L)^{2} T_{t}=\xi_{0 t-1}$ & $\left(1-2 \cos \left(\omega_{j}\right) L+L^{2}\right)^{2} s_{t}^{p_{j}}=\left(\sqrt{\frac{\cos \left(2 \omega_{j}\right)}{\gamma_{j}^{\star} \eta_{j}^{\star}}}\right)\left(1-\theta_{j}^{1} L-\theta_{j}^{2} L^{2}\right) \xi_{j-1}$ & $(1+L)^{2} s_{t}^{2}=\xi_{R t-1}$ \\
\hline
\end{tabular}

$\mathrm{a} \phi_{j}^{\alpha}(L)=\left[1-2 \alpha_{j} \cos \left(\omega_{j}\right) L+\alpha_{j}^{2} L^{2}\right], \phi_{j}^{\beta}(L)=\left[1-2 \beta_{j} \cos \left(\omega_{j}\right) L+\beta_{j}^{2} L^{2}\right], \gamma_{j}^{\star}, \mathrm{y} \eta_{j}^{\star}$ are given in Eq. (A.11), and $\theta_{j}^{1}=\gamma_{j}^{\star}+\eta_{j}^{\star} ; \theta_{j}^{2}=-\gamma_{j}^{\star} \eta_{j}^{\star}$. 


\section{The new linear dynamic harmonic regression (LDHR) algorithm}

From the original NVR optimization algorithm (Young et al., 1999) two questions arise. First, the logarithmic transformation is used because it produces a more clearly located and defined optimum, so facilitating the accurate computation of the estimated hyper-parameters: hence, the original algorithm uses a non-linear objective function. But, the computational complexity of the algorithm largely increases. Second, when minimizing the objective functions in (5) and (6), the regions immediately around the poles must be avoided since the DHR model elements are nonstationary, so their spectral peaks are poles (in this context, a pole is a point in the real line, say $\omega_{0}$, such that $f(\omega)$ approaches infinity as $\omega$ approaches $\left.\omega_{0}\right)$. Our new proposal is to simplify this approach by estimating the $N V R$ hyperparameters using only an alternative quadratic objective function in the whole frequency domain. To do so, a linear algebraic transformation of (5), capable of eliminating the poles in $f_{d h r}\left(\omega, \boldsymbol{\sigma}^{2}\right)$ and $f_{y}(\omega)$, is needed.

\subsection{A linear algebraic transformation}

In the optimization process, we seek the vector $\sigma^{2}$ that minimizes

$$
\min _{\left[\boldsymbol{\sigma}^{2}\right] \in \mathbb{R}^{R+2}}\left\|f_{y}(\omega)-f_{d h r}\left(\omega, \boldsymbol{\sigma}^{2}\right)\right\| .
$$

But it has been shown that the DHR components could follow non-stationary ARMA processes, so that $f_{d h r}\left(\omega, \boldsymbol{\sigma}^{2}\right)$ could have poles; and then the norm is not defined. In order to re-state Eq. (10), we need to eliminate the AR roots on the unit circle. Using the ARMA representation of the DHR components $s_{t}^{p_{j}}$, we can rewrite the pseudo-spectrum of the DHR model as

$$
f_{d h r}\left(\omega, \sigma^{2}\right)=\sigma_{e}^{2}+\sum_{j=0}^{R} \sigma_{j}^{2} \frac{\theta_{j}\left(\mathrm{e}^{-\mathrm{i} \omega}\right) \theta_{j}\left(\mathrm{e}^{\mathrm{i} \omega}\right)}{\varphi_{j}\left(\mathrm{e}^{-\mathrm{i} \omega}\right) \varphi_{j}\left(\mathrm{e}^{\mathrm{i} \omega}\right)} ;
$$

where $\varphi_{j}(L)$ and $\theta_{j}(L)$ are the AR and MA polynomials of the ARMA model of $s^{p_{j}}$.

We use the periodogram as an spectral estimate of $f_{y}(\omega)$. Then, if $B_{y}(L)$ denotes the AR polynomial fitted to the observed time series, $f_{y}(\omega)$ can be substituted by $\widehat{f_{y}}(\omega)=\widehat{I_{a}}(\omega) \cdot\left[B_{y}\left(\mathrm{e}^{-\mathrm{i} \omega}\right) B_{y}\left(\mathrm{e}^{\mathrm{i} \omega}\right)\right]^{-1}$, where $\widehat{I_{a}}(\omega)$ is the periodogram of the filtered time series $a_{t}=B_{y}(L) y_{t}$. Hence, we can rewrite (10) as

$$
\min _{\left[\sigma^{2}\right] \in \mathbb{R}^{R+2}} \mid \frac{\widehat{I_{a}}(\omega)}{B_{y}\left(\mathrm{e}^{-\mathrm{i} \omega}\right) B_{y}\left(\mathrm{e}^{\mathrm{i} \omega}\right)}-\left[\sigma_{e}^{2}+\sum_{j=0}^{R} \sigma_{j}^{2} \frac{\theta_{j}\left(\mathrm{e}^{-\mathrm{i} \omega}\right) \theta_{j}\left(\mathrm{e}^{\mathrm{i} \omega}\right)}{\varphi_{j}\left(\mathrm{e}^{-\mathrm{i} \omega}\right) \varphi_{j}\left(\mathrm{e}^{\mathrm{i} \omega}\right)}\right] \| .
$$

In order to align the spectral peaks of the DHR components with those of the estimated spectrum $\widehat{f_{y}}(\omega)$, the components can be chosen so that the full DHR model has all the unit roots of $B_{y}(L)$. Then, we can split each polynomial $\varphi_{j}(z)$ in $\varphi_{j}(z)=\phi_{j}(z) * \Phi_{j}(z)$, where $\Phi_{j}(z)$ has the unit roots and $\phi_{j}(z)$ has the remaining roots. Multiplying (12) by $\Psi(\omega)=\prod_{h=0}^{R} \Phi_{h}\left(\mathrm{e}^{-\mathrm{i} \omega}\right) \Phi_{h}\left(\mathrm{e}^{\mathrm{i} \omega}\right)$, we have

$$
\min _{\left[\sigma^{2}\right] \in \mathbb{R}^{R+2}}\left\|\frac{\widehat{I_{a}}(\omega) \cdot \Psi(\omega)}{B_{y}\left(\mathrm{e}^{-\mathrm{i} \omega}\right) B_{y}\left(\mathrm{e}^{\mathrm{i} \omega}\right)}-\sigma_{e}^{2} \Psi(\omega)-\sum_{j=0}^{R} \sigma_{j}^{2} \frac{\theta_{j}\left(\mathrm{e}^{-\mathrm{i} \omega}\right) \theta_{j}\left(\mathrm{e}^{\mathrm{i} \omega}\right) \prod_{j \neq h} \Phi_{h}\left(\mathrm{e}^{-\mathrm{i} \omega}\right) \Phi_{h}\left(\mathrm{e}^{\mathrm{i} \omega}\right)}{\phi_{j}\left(\mathrm{e}^{-\mathrm{i} \omega}\right) \phi_{j}\left(\mathrm{e}^{\mathrm{i} \omega}\right)}\right\|,
$$

(cf. Bell, 1984, Eqs. (1.4)-(1.6)). Hence, the new proposed algorithm minimizes

$$
\min _{\boldsymbol{\sigma}^{2} \in \mathbb{R}^{R+2}}\left\|\Psi(\omega) \cdot\left[\widehat{f}_{y}(\omega)-f_{d h r}\left(\omega, \boldsymbol{\sigma}^{2}\right)\right]\right\| .
$$

This objective function is quadratic and can be evaluated solving a linear system over the whole range $[-\pi, \pi]$ because $\Psi(\omega) \cdot \widehat{f}_{y}(\omega)$ and $\Psi(\omega) \cdot f_{d h r}\left(\omega, \sigma^{2}\right)$ do not have poles. Moreover, Eq. (14) can be minimized by ordinary least squares OLS to obtain the estimation of $\sigma^{2}=\left[\sigma_{e}^{2}, \sigma_{d h r}^{2}\right]^{\prime}$, so simplifying the estimation algorithm; therefore, it is faster and more accurate than the analogous optimization of the DHR procedure. 


\subsection{Improving the spectral fitting}

One problem with the formulation of the optimization problem in the previous section is that, if the order $p$ of $B_{y}(L)$ is large enough, $B_{y}(L)$ has additional roots that are not included in the DHR model. These additional roots produce additional spectral peaks in the estimated spectrum, $\widehat{f_{y}}(\omega)$, but these peaks are not associated with any spectral peak of the pseudo-spectrum of the DHR model, $f_{d h r}\left(\omega, \sigma^{2}\right)$.

Because the pseudo-spectra are positive definite functions, they cannot be mutually orthogonal. Therefore, the additional spectral peaks affect the spectral fitting of the DHR components. The magnitude of this influence depends on the modulus of each additional root and on the location of its corresponding spectral peak. For example, when Young et al. (1999) add a long period component into the DHR model and use an AR(54) spectrum they find: "The main problem with this high-order AR(54) spectrum is that ...it injects obviously spurious peaks and distortions ...making estimation of the NVR parameters more difficult ...". In order to overcome the problem, Young et al. (1999) concatenate a low-order spectrum with a high-order spectrum, "using the higher-order AR spectrum to define the lower-frequency cyclical band of the spectrum, and the lower-order spectrum to specify the higher-frequency seasonal behavior".

Within the present context, we propose a different approach to handling spurious peaks. In order to avoid the effect of the additional peaks introduced by the above analysis, we fit these spurious peaks with additional components and so isolate the spectral fitting of the DHR model from the distortions due to the spurious peaks. Therefore, a two-stage procedure is proposed.

\subsubsection{First stage}

In the first stage, the vector of variances $\boldsymbol{\sigma}_{d h r}^{2}$ is estimated using additional components. For each additional peak (due to an additional AR root or complex pair of additional AR roots in $B_{y}(L)$ ) an additional component is included (the models for these additional components are explained in the next section).

Let $f_{a c}\left(\omega, \boldsymbol{\sigma}_{a c}^{2}\right)$ be the pseudo-spectrum of the sum of the additional components:

$$
f_{a c}\left(\omega, \boldsymbol{\sigma}_{a c}^{2}\right)=\sum_{h=R+1}^{k} \sigma_{h}^{2} S_{h}(\omega)
$$

where $\sigma_{h}^{2} S_{h}(\omega)$ is the pseudo-spectrum of the $h$ th additional component; $\sigma_{a c}^{2}=\left[\sigma_{R+1}^{2}, \ldots, \sigma_{k}^{2}\right]$ is the vector of the variances of the innovations of the additional components; and $k+1$ is the number of spectral peaks of $\widehat{f}_{y}(\omega)$ associated to $\mathrm{AR}$ roots of $B_{y}(L)$.

In this first stage,

$$
\min _{\left[\boldsymbol{\sigma}_{d h r}^{2}, \boldsymbol{\sigma}_{a c}^{2}\right] \in \mathbb{R}^{k+1}}\left\|\Psi(\omega) \cdot\left[\widehat{f}_{y}(\omega)-\sum_{j=0}^{R} \sigma_{j}^{2} S_{j}(\omega)-\sum_{h=R+1}^{k} \sigma_{h}^{2} S_{h}(\omega)\right]\right\|
$$

is minimized by OLS, and the estimated variances of the innovations of the DHR components $\widehat{\boldsymbol{\sigma}}_{d h r}^{2}$ are obtained.

\subsubsection{Second stage}

In the second stage, the variance of the irregular component $\sigma_{e}^{2}$ is estimated by minimizing

$$
\min _{\sigma_{e}^{2} \in \mathbb{R}}\left\|\Psi(\omega) \cdot\left[\widehat{f}_{y}(\omega)-\sum_{j=0}^{R} \widehat{\sigma}_{j}^{2} S_{j}(\omega)-\sigma_{e}^{2}\right]\right\|
$$

by OLS, using the estimated values $\widehat{\boldsymbol{\sigma}}_{d h r}^{2}$ from the first stage. Finally, we compute $\widehat{\boldsymbol{\sigma}}^{2}=\left[\widehat{\boldsymbol{\sigma}}_{e}^{2}, \widehat{\boldsymbol{\sigma}}_{d h r}^{2}\right]^{\prime}$, and $\widehat{\mathbf{N V R}}=\widehat{\boldsymbol{\sigma}}_{d h r}^{2} / \widehat{\sigma}_{e}^{2}$. Note that the two-stage algorithm described earlier is completely linear and does not require the avoidance of any region around the poles. 


\section{An heuristic identification algorithm}

With the new algorithm described earlier, the variances and the NVR hyper-parameters are estimated by unrestricted OLS, and so it is possible to obtain estimates that have negative values. If the identification of the DHR model is incorrect the probability of negative OLS estimated values increases. For this reason, we need a well-identified DHR model specification, i.e., one that provides a DHR model with a spectrum of similar shape to the shape of the spectrum of the observed time series. In practice, when negative values are found our algorithm uses non-negative least squares (NNLS) estimation as suggested by Lawson and Hanson (1974). In this section, we propose a simultaneous identification and estimation algorithm. To illustrate our procedure we will be using two data sets of different length. Namely, the logarithm of the monthly Peruvian Exports (PE) from January 1994 to February 2006 (146 observations), and the logarithm of the Spanish Industrial Production Index (IPI) from January 1975 to March 2002 (336 observations).

\subsection{Selecting the DHR components from $B_{y}(L)$}

Our identification procedure consists of two steps: firstly, we identify the AR roots of $B_{y}(L)$ associated to the frequencies of the components to be estimated with the DHR model (usually the trend and the periodic components), and secondly, for each frequency, we choose the DHR model whose $\alpha_{j}$ and $\beta_{j}$ parameters are equal to the modulus of the AR roots of $B_{y}(L)$ associated to that frequency.

\subsubsection{First step}

The PE series (see Fig. 4(a)) shows a clear trend and seasonal patterns. For this reason, the "a priori" DHR model should have DHR components associated to the frequencies $\omega_{j}=2 \pi j / 12, j=0, \ldots, 6$, so the model should explain the oscillation of the time series around $P_{j}=\infty, 12,6,4,3,2.4,2$ periodicities, if these are all clearly identified in the empirical spectrum.

To illustrate the first step, an AR(34) model is fitted to the PE series (this is the AR order suggested by our identification algorithm, see Section 5.2 for an explanation). Some of the roots of the $\operatorname{AR}(34)$ polynomial $B_{y}(L)$ fitted to the series are close to the $P_{j}$ periodicities. (See the roots marked by dots in Fig. 1.) These are the AR roots associated to the DHR components.

In order to decide whether or not an AR root is associated to the $j$ th DHR component of periodicity $P_{j}$, we use a simple criterion. We fix a range of frequencies $\pm \varepsilon$ radians around each $\omega_{j}=2 \pi / P_{j}$. If the $\omega$ frequency associated to an AR root lies inside any range, i.e., if $\left|\omega_{j}-\omega\right| \leqslant \varepsilon$, then this AR root is associated to the $j$ th DHR component. The default (heuristic) values, $\varepsilon$, used in our program are $2 \pi / 600$ radians for the seasonal components, and $2 \pi / 36$ radians for the trend. The range for the trend component is wider in order to incorporate the roots associated to cyclical periods in the trend. This allows us to estimate long term cyclical components, typically those longer than three years.

The cases where the above condition is fulfilled are indicated by dots in Fig. 1; these correspond to the roots that lie inside the regions around each frequency $\omega_{j}$ (see Table 3). In this example there are two AR unit roots associated to the trend $T$ and there is one pair of conjugate AR unit modulus roots associated to the seasonal components $s^{12}, s^{6}, s^{4}$ and $s^{2.4}$; two conjugate pairs of roots associated to the seasonal $s^{3}$ and one stationary root associated to $s^{2}$.

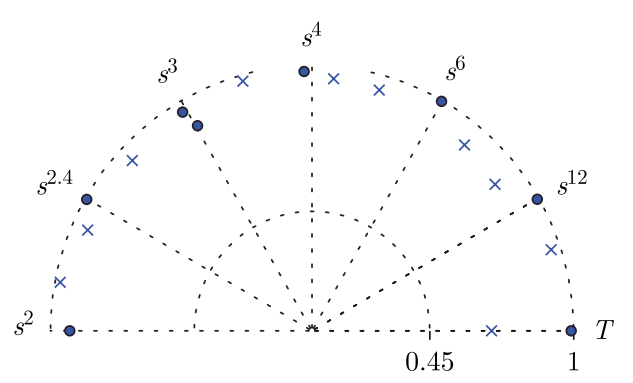

Fig. 1. AR(34)-roots of the AR(34) polynomial $B_{y}(L)$ fitted to the PE series. 
Table 3

Roots of the AR(34) polynomial $B_{y}(L)$ used in the identification process (marked by dots in Fig. 1)

\begin{tabular}{|c|c|c|c|c|c|}
\hline Roots & & Period & Norm & Component & Model \\
\hline 1.00 & $\pm 0.00 i$ & $\infty$ & 1.00 & \multirow{2}{*}{$T$} & \multirow[t]{2}{*}{ IRW } \\
\hline 1.00 & $\pm 0.00 i$ & $\infty$ & 1.00 & & \\
\hline 0.86 & $\pm 0.50 i$ & 12.038 & 0.99 & $s^{12}$ & RW \\
\hline 0.49 & $\pm 0.86 i$ & 5.980 & 1.00 & $s^{6}$ & RW \\
\hline-0.03 & $\pm 0.98 i$ & 3.922 & 0.98 & $s^{4}$ & RW \\
\hline-0.44 & $\pm 0.77 i$ & 3.012 & 0.89 & \multirow{2}{*}{\}$s^{3}$} & \multirow[t]{2}{*}{ SRW } \\
\hline-0.49 & $\pm 0.82 i$ & 2.976 & 0.96 & & \\
\hline-0.86 & $\pm 0.49 i$ & 2.398 & 0.99 & $s^{2.4}$ & RW \\
\hline-0.93 & $\pm 0.00 i$ & 2.000 & 0.93 & $s^{2}$ & RW \\
\hline
\end{tabular}

\subsubsection{Second step}

The most prominent spectral peaks of $\widehat{f}_{y}(\omega)$ are due to the AR roots whose modulus are close to one. If we use DHR models with the same AR roots, the pseudo-spectrum of the DHR model should have a similar shape to the shape of the estimated spectrum $\widehat{f}_{y}(\omega)$. Therefore, given the DHR components of the model (step one), the models for the components are chosen so that, in each case, their $\alpha_{j}$ and $\beta_{j}$ parameters are equal to the inverse of the modulus of the AR roots of $B_{y}(L)$. When these moduli are close to one (for a default value larger than 0.95), an $\alpha_{j}$ and/or $\beta_{j}$ parameters equal to one can be imposed. For the spurious peaks, we use as additional models the corresponding partial fractions from the expansions of $1 / B_{y}(L)$ (see Section 4.2). With the new identification criterion, if an AR(34) is used, the algorithm identifies an IRW model for the trend, and RW models for the all the seasonal harmonics except $s^{3}$ and $s^{2}$, that follow SRW and AR models, respectively (see Fig. 1 and Table 3). These heuristic rules, about the modulus and the angle of the roots, seem to work well in most of the cases but, of course, they can be replaced by formal statistical tests if the user wishes to do so.

\subsection{Selecting the order of the $B_{y}(L)$}

The identification procedure of the DHR model depends on the estimated AR polynomial $B_{y}(L)$. Since our estimation procedure is very fast, it is possible to use a wide range of $p$ orders and to identify and estimate one DHR model for each $\operatorname{AR}(p)$ polynomial $B_{y}(L)$. Among the alternative DHR models, it is possible to select one of them under certain criteria. When, for all AR( $p)$ polynomials, the same type of model is identified, a criterion that provides good results is choosing the DHR model whose estimated variances $\widehat{\boldsymbol{\sigma}}_{d h r}^{2}$ are closer to the median values. When this is not the case and different models are identified for different AR orders, the recourse is to choose the DHR model whose residual spectrum, i.e., the transformed difference between $\widehat{f}_{y}(\omega)$ and the sum of pseudo-spectra of the DHR components

$$
\Psi(\omega) \cdot \widehat{f}_{y}(\omega)-\Psi(\omega) \cdot \sum_{j=0}^{R} \widehat{\sigma}_{j}^{2} S_{j}(\omega),
$$

has the shape closest to the shape of a white noise spectrum (in terms of maximum $R^{2}$ statistic).

The results obtained with the LDHR and CAPTAIN algorithms are shown in Table 4 . The spectra fitted by this procedure and by SEATS are shown in Fig. 2. Due to the low resolution of the periodogram (the PE series has only 146 data) it is difficult to see the differences between both procedures. Therefore we also provide the spectral fitting of another example: the Spanish IPI data with 336 observations.

For the PE series, the identifications suggested by CAPTAIN and LDHR differ slightly since a different model is proposed for the $s^{3}$ component, and the $s^{2}$ component is absent in CAPTAIN. Also the orders of the AR polynomials are different (34 for LDHR and 19 for CAPTAIN) so strict comparisons among the estimated NVRs may be distorted by differences in the suggested identifications. As regards computational speed, LDHR is almost three times faster than CAPTAIN. In the case of the IPI series, however, the same DHR model is proposed by both procedures and the resulting AR(32) order is also identical in both cases. Again LDHR is faster than CAPTAIN and, in general, estimated NVRs values are higher in LDHR although these differences have negligible consequences in practice. 
Table 4

Estimation results for PE and IPI using both LDHR and CAPTAIN

\begin{tabular}{|c|c|c|c|c|c|c|c|c|}
\hline \multirow[t]{3}{*}{ Component } & \multicolumn{4}{|l|}{ PE series } & \multicolumn{4}{|c|}{ IPI series } \\
\hline & \multicolumn{2}{|c|}{ LDHR (0.07 secs) } & \multicolumn{2}{|c|}{ CAPTAIN (0.22 secs) } & \multicolumn{2}{|c|}{ LDHR (0.08 secs) } & \multicolumn{2}{|c|}{ CAPTAIN (0.19 secs) } \\
\hline & $\widehat{N V R}$ & DHR model & $\widehat{N V R}$ & DHR model & $\widehat{N V R}$ & DHR model & $\widehat{N V R}$ & DHR model \\
\hline$T$ & 0.00022 & IRW & 0.00009 & IRW & 0.0054 & IRW & 0.0029 & IRW \\
\hline$s^{12}$ & 0.00926 & RW & 0.04757 & RW & 0.0513 & RW & 0.0110 & $\mathrm{RW}$ \\
\hline$s^{6}$ & 0.00103 & RW & 0.00812 & RW & 0.0540 & RW & 0.0104 & RW \\
\hline$s^{4}$ & 0.02041 & RW & 0.01227 & RW & 0.0802 & RW & 0.0129 & RW \\
\hline$s^{3}$ & 0.00017 & SRW & 0.00132 & RW & 0.0481 & RW & 0.0073 & RW \\
\hline$s^{2.4}$ & 0.00428 & RW & 0.00915 & RW & 0.0463 & RW & 0.0085 & RW \\
\hline$s^{2}$ & 0.00386 & AR & & - & 0.0431 & RW & 0.0072 & RW \\
\hline
\end{tabular}
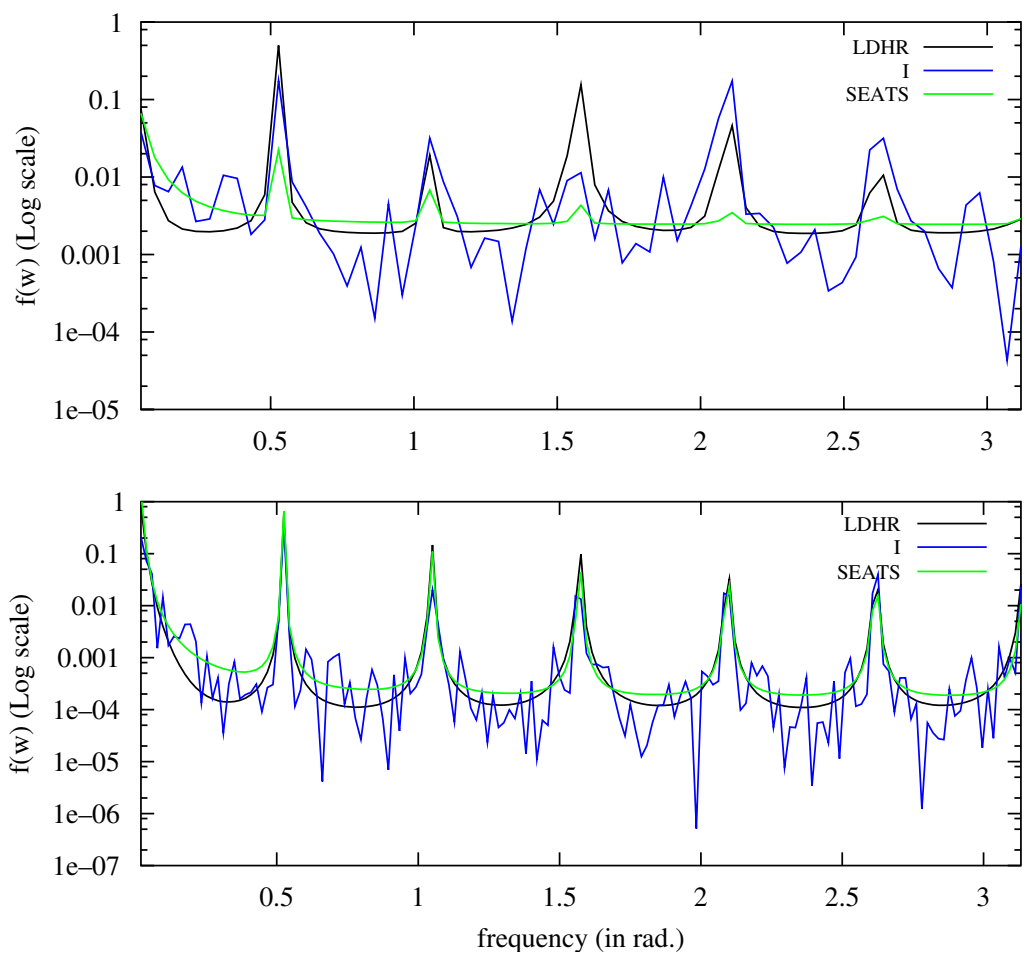

Fig. 2. Spectral fitting of the DHR and SEATS models to the periodogram of the PE series (above) and IPI series (below).

In Fig. 3 we compare the trend filter gain for SEATS and LDHR in both series. The largest differences are observed for the PE series. While the LDHR trend seems more stable than the corresponding trend in SEATS, the opposite happens with the seasonal components, see Maravall (1993) (similar evidences also shown in Fig. 4). The homogeneous behaviour of the harmonics in SEATS, as compared with LDHR, is remarkable (note the differences between $s^{6}$ and $s^{4}$ in the trend filter gain of LDHR). For the case of IPI, however, both procedures show similar homogeneity for the harmonics but again the trend is slightly more stable (smoother) than the one obtained by SEATS (and again the opposite happens with the seasonal components).

Fig. 2 shows the spectral fit of both SEATS and LDHR fitted to the periodogram of both PE and IPI series, contrary to what is observed for PE, visual differences are more obvious. In the case of IPI, the differences are clearly obvious. 

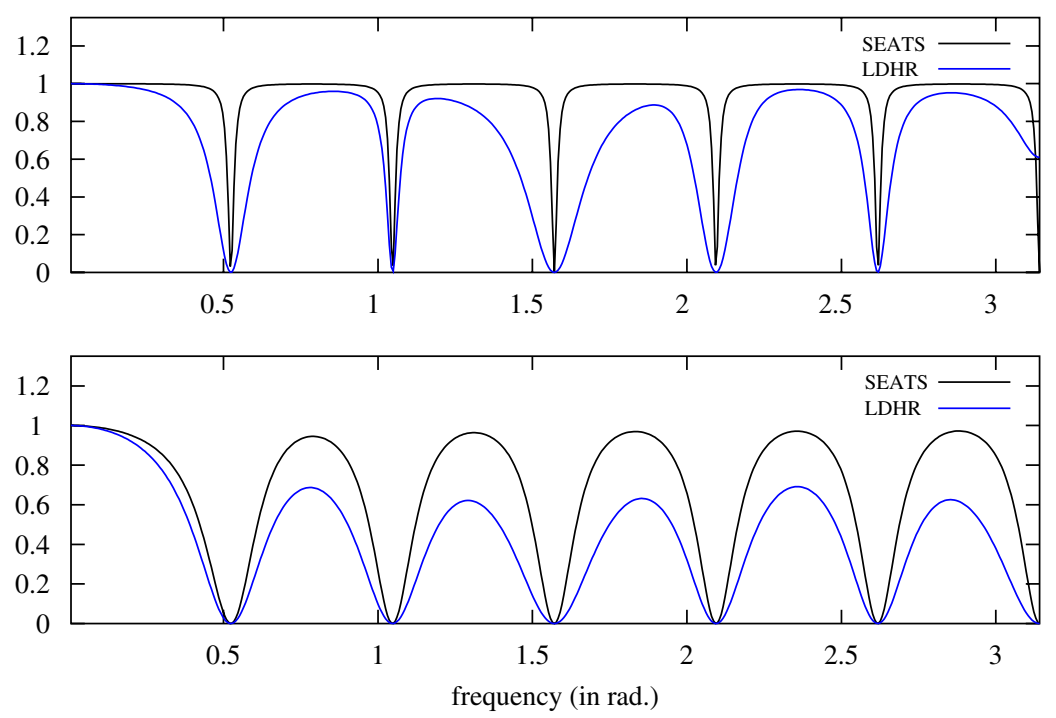

Fig. 3. Trend filter gain of SEATS and LDHR for the PE series (above) and IPI series (below).

Note, however, that the comparison between SEATS and LDHR in this regard is, somehow, unfair since the objective function in SEATS does not contemplate the fitting of the periodogram.

The estimated DHR components of the PE series are shown in Fig. 4. We have computed the smoothed estimates of the components using the function e $4 \mathrm{trend}$. $\mathrm{m}$ (Casals et al., 2000, 2002). ${ }^{2}$ The largest differences between SEATS and LDHR are observed when looking at the first difference of the trends (derivative). As found in García-Ferrer and Bujosa-Brun (2000) for a large number of international IPI data sets, the SEATS's derivative is much more volatile (indicative of less smooth trend) than the one obtained by LDHR. Nevertheless, the seasonal components shown in Fig. 4(c) indicate more stability in the case of SEATS than the one shown by the LDHR's seasonal components. However, as Pollock pointed out in a personal communication, this is an inevitable consequence of the narrower notches in the amplitude response of the trend estimation filter of SEATS, which implies that a more restricted set of sinusoids participate in the Fourier synthesis of the seasonal fluctuations.

\section{Simulation results}

Monthly time series are generated using an IRW model $\left(\sigma_{T}^{2}=5\right)$ for the trend, while the seasonals are modulated by an RW process $\left(\sigma_{s}^{2}=50\right)$. Four alternative values for the noise variance are specified $\left(\sigma_{e}^{2}=1000,5000,10000\right.$, and $50000)$ and four sample sizes are used $(N=150,300,450$, and 600). For each of the 16 cases, 1000 time series are generated.

The default values used in the identification process are the following: (a) the range of AR models goes from AR(16) to AR(36); (b) AR roots with modulus larger than 0.95 and associated to the DHR components (see Section 5.1) are taken as unit modulus roots; and (c) all AR roots with modulus smaller than 0.45 are not associated with any DHR component.

\subsection{Estimation with no identification}

Assuming that the true model is known, the LDHR algorithm presented in Section 4 is used to estimate the eight variances $\widehat{\boldsymbol{\sigma}}^{2}=\left[\widehat{\sigma}_{e}^{2}, \widehat{\boldsymbol{\sigma}}_{d h r}^{2}\right]^{\prime}$. The seven hyperparameters are then calculated as $\widehat{\mathbf{N V R}}^{\prime}=\widehat{\boldsymbol{\sigma}}_{d h r}^{2} / \widehat{\sigma}_{e}^{2}$. Tables A2 and A3 summarize the main results, showing the median and inter-quartile range (IQR) of the estimated parameters.

\footnotetext{
${ }^{2}$ It is included in a MATLAB toolbox for time series modeling called E4, which can be downloaded at http://www.ucm.es/info/icae/e4.
} 
a

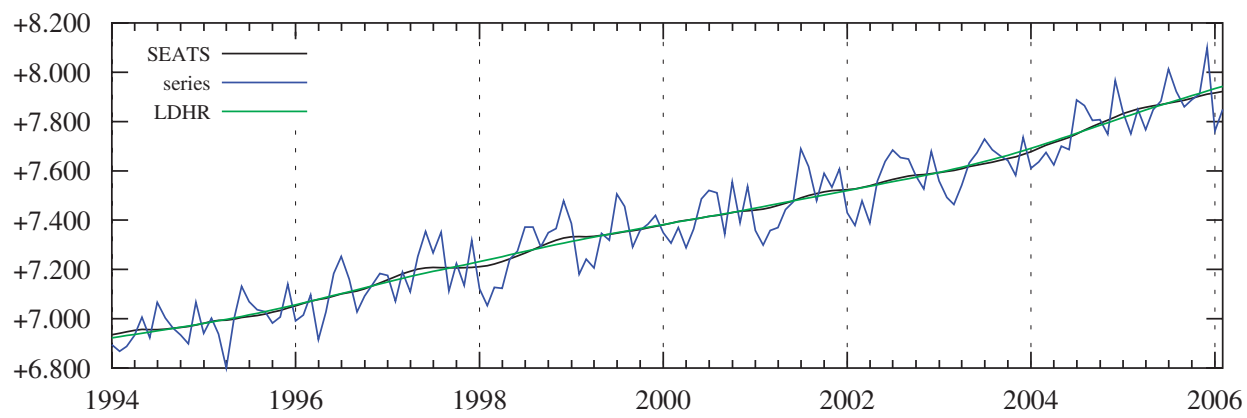

b

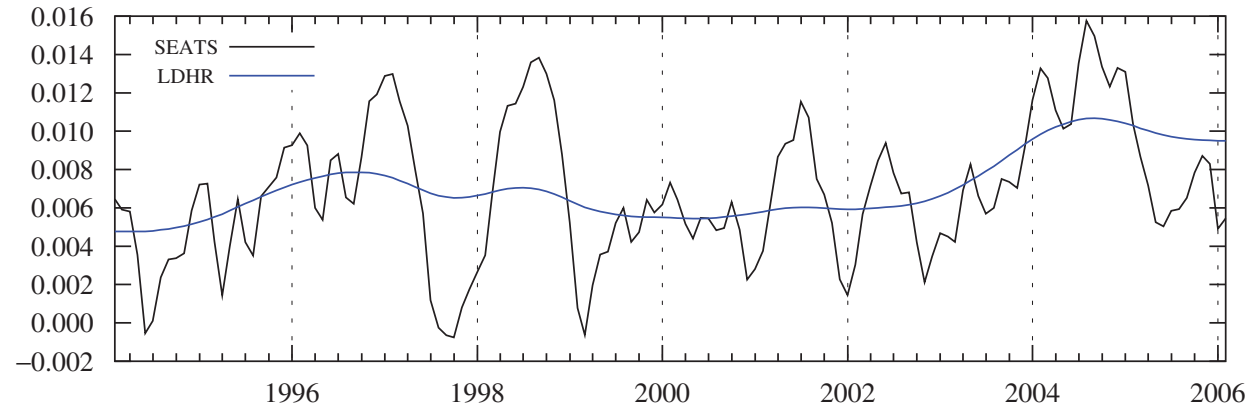

C

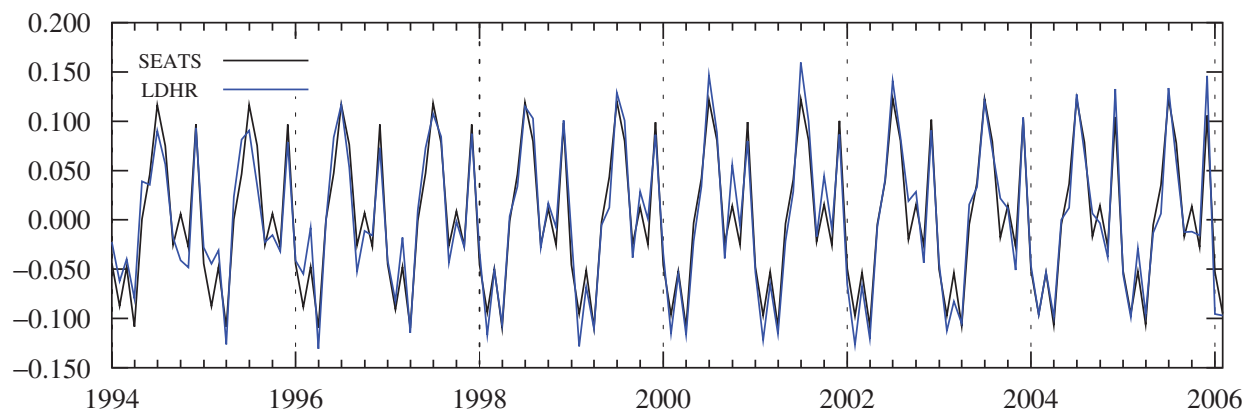

d

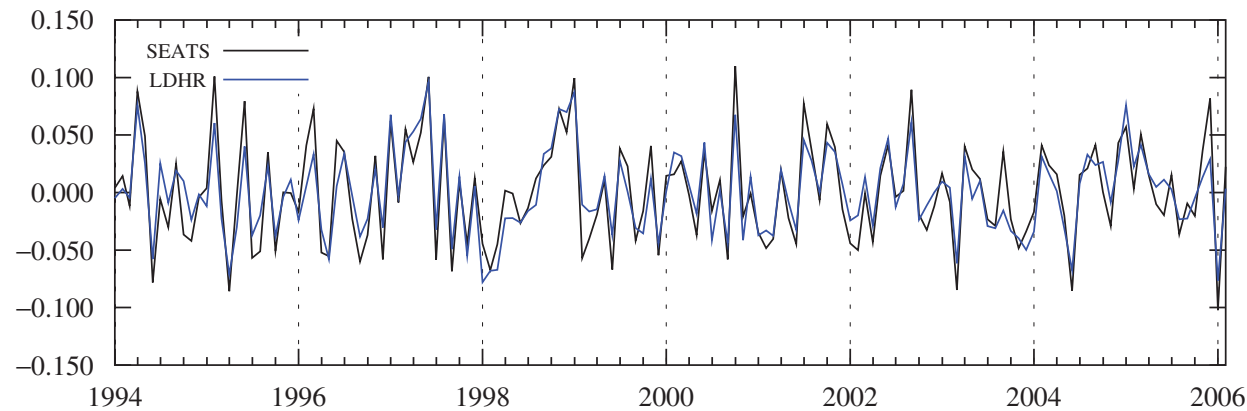

Fig. 4. The estimated unobserved components for the PE series with the LDHR algorithm and SEATS. (a) Series and trend; (b) first difference of trend (c) seasonal component; and (d) irregular component.

As expected, the larger the sample, the lower the bias and dispersion of the estimates of both the variances and noise variance ratio (NVR) hyperparameters. For high noise levels, the estimation results worsen. In particular, the estimated variances of the DHR components tend to be larger than the true values, while the opposite happens to the variance of the irregular component. However, the results are satisfactory since the bias in the estimated NVR values appears 
negligible in terms of its effect on the filtered components, i.e., the final estimation of the trend and the seasonals by the Kalman filter and FIS algorithms (see Young et al., 1999). The number of times that NNLS is needed to avoid negative variance estimation is relatively small, and more frequent in situations showing a high noise level. In this regard, note that medians and inter-quality range (IRQ) values are computed only for OLS estimations. For purposes of comparison, we have repeated in Table A4 a similar exercise using CAPTAIN. There, we can observe that the level of the noise has less effect on the estimates, probably due to the fact that in CAPTAIN the variance of the irregular component is estimated from the residuals of the AR model (see Step (1) of Section 2).

\subsection{Identification and estimation}

In this case, a more realistic exercise is carried out: here, the true model is assumed to be unknown and, therefore, the only information provided to the algorithm is the time series data, its periodicity as well as the heuristic default values suggested in Section 5. A large number of models are considered for the DHR components: namely AR(1), AR(2), RW, SRW, and IRW specifications. For $s^{2}$ (by default) only models with one root (AR(1) or RW) are allowed. Otherwise, real negative roots in the AR polynomial $B_{y}(L)$ are assigned to this component and the algorithm tends to identify AR(2), SRW or IRW, in most cases. For the same reason, only models with at most two (real positive) roots for the trend are allowed. We refer to 'unrestricted identification' when the algorithm chooses, for each DHR component, one among the former family of models. Conversely, in 'restricted identification', only the subset of AR(1) or RW process for the seasonals are considered.

In order to conserve space, we show only the estimation of DHR components with real AR-roots (trend and $S_{2}$ ) and one DHR component with complex AR-roots (the $S_{4}$ DHR component), since all results for DHR components with complex AR-roots are very similar (see Tables A2 and A3). Tables A5 to A8 show the statistics computed only over the cases of OLS estimations and correct identification (see Table A1). The complete set of tables is available from the authors upon request.

\subsubsection{Restricted identification}

The percentage of successful identifications is quite large (see footnote in Table A1) except when the noise level is high. Note how the number of times that NNLS is required is inversely related to the percentage of successful identifications. Therefore the NNLS requirement may provide an indication of an incorrect identification.

\subsubsection{Unrestricted identification}

Here, the results are very similar to those in the previous case. The percentage of correct identifications is quite large (see footnote in Table A1), although the size of the bias and the dispersion decrease slightly (Tables A7 and A8). Note, however, that these results apply only to OLS estimates with correct model indentification.

Finally, if the rule 'only AR roots with modulus larger than 0.95 are taken as unit modulus roots' is modified by increasing the critical value to 0.9999 , OLS always delivers positive estimates. When the rules of the identification procedure are changed in this manner, none of the 16000 replications provide negative estimated values $(8 \times 16000$ variances estimated by unrestricted OLS are positive, with both the restricted and the unrestricted identification procedures). Obviously, with the new rule, the probability of correct identification is smaller than before. In order to allow the user to select different alternatives, the toolbox allows for easy modification of these rules.

\section{Conclusions}

Among the available stochastic unobserved components alternatives, the dynamic harmonic regression (DHR) model has been used extensively over the past two decades in different areas of research, such as economic, business, environmental and biological applications. It is a powerful signal extraction and forecasting tool that can compete well with other known alternatives. The oscillations of each DHR component are modulated by stochastic time-varying parameters within the family of generalized random walk (GRW) models, which was suggested by the third author many years ago and subsumes a large number of the more specific characterizations (e.g. RW, IRW SRW processes) found in the signal extraction literature.

In the first part of this paper, we show that each DHR component has an Autoregressive moving average (ARMA) representation. In particular, we show that, for each cyclical and seasonal component, there is a sequence of real numbers such that its extended Fourier transform is the pseudo-spectrum of the component. We have also shown the existence 
of an ARMA model whose pseudo-covariance generating function is, precisely, the aforementioned sequence. The consequence of these results is that the DHR model can be written as a sum of certain ARMA models, plus a white noise process.

In the second part of the paper, we propose an alternative algorithm to estimate the model hyper-parameters that makes use of a linear algebraic transformation in order to eliminate the poles in the original objective function. Once these poles are removed, simple ordinary least squares can be used for simultaneous identification and estimation of the hyper-parameters. As a result, the only input information required by the LDHR algorithm is the raw time series data, the nature of its periodicity, e.g. monthly, quarterly, etc., and the knowledge of the heuristic default values used in the identification algorithm. This should be an advantage in relation to existing alternatives that require additional input information from the user.

We make two further comments regarding future developments. First, our results can be easily extended to some other well-known alternatives mentioned earlier, in as far as they can be treated as special cases of the generalized random walk specifications. Second, in this paper, we have concentrated on signal extraction and we have not yet tried to analyse the forecasting performance of the new algorithm. This will be the subject of future research. Given the similarities of the LDHR and DHR procedures, we might expect similarities in forecasting ability and only when trend models differ considerably, should we expect the prediction results to be too different.

Finally, it should be noted that the identification and estimation results discussed in Sections 4 and 5 have been carried out using our toolbox LDHR for GNU/octave. ${ }^{3}$ This toolbox ${ }^{4}$ makes use of several functions of the signal processing and communications (SPC) toolbox for Matlab; ${ }^{5}$ and the $E^{4}$ toolbox. $^{6}$

\section{Acknowledgements}

We are very thankful to Professors D.S.G. Pollock and Agustin Maravall for very helpful comments and for providing the Peruvian Exports data. We also thank comments provided by five referees that were extremely helpful in revising previous versions of this paper. The preparation of this paper and the research that it describes have been supported by the Comunidad Autónoma de Madrid/UAM and the Spanish MEC projects 09-SHD/011 and SEJ 2006-04957.

\section{Appendix A.}

\section{A.1. Monte Carlo tables}

The times of successful identification, the times the NNLS algorithm is used, and the times the NNLS algorithm is used when the algorithm correctly identifies the true model are shown in Table A1. In Tables A2 and A3, the estimation results (when the true model is provided to the algorithm) are shown. For purposes of comparison, Table A4 is similar to Table A3, but using CAPTAIN. Tables A5-A8 show the results when the algorithm both identifies the model and estimates the parameters. Tables A2-A8 show the statistics computed only over the cases of OLS estimations and correct identification.

\section{A.2. Data definition and sources}

The source of the Peruvian Exports (PE) data, from January 1994 to February 2006, is Banco Central de Reserva del Perú, and according to the TRAMO program no outliers or other intervention effects are present this series.

The source of Spanish Industrial Production Index (IPI), from January 1975 to March 2002, is the Spanish Instituto Nacional de Estadística. Outliers, trayding days and Easter effects have been corrected by TRAMO (Maravall, 2006).

\section{A.3. Inverse $(b)^{-1}$ เ}

Because we deal with non-stationary models it is necessary to use an inverse of the sequences that provides a well-defined pseudo-covariance generating function, $\Lambda_{T}(z)$. Should we define the cograde of a non-null sequence $b$

\footnotetext{
${ }^{3}$ http://www.octave.org/.

${ }^{4}$ which can be freely downloaded from http://www.ucm.es/info/ecocuan/mbb/ldhr/.

${ }^{5}$ http://www.cs.cmu.edu/afs/cs/project/ai-repository/ai/areas/speech/systems/spctools/0.html.

${ }^{6} \mathrm{http}: / /$ www.ucm.es/info/icae/e4/
} 
Table A1

Times of success in identification. Times NNLS algorithm is used. Times NNLS algorithm is used with correct identification

\begin{tabular}{|c|c|c|c|c|c|c|c|c|}
\hline & \multirow[t]{3}{*}{ Noise level } & \multirow{3}{*}{$\begin{array}{l}\text { Estimation only } \\
\text { NNLS algorithm }\end{array}$} & \multicolumn{3}{|c|}{ Restricted identification } & \multicolumn{3}{|c|}{ Unrestricted identification } \\
\hline & & & \multirow[b]{2}{*}{ Right ident $^{\mathrm{a}}$} & \multicolumn{2}{|c|}{ NNLS algorithm } & \multirow[b]{2}{*}{ Right ident $^{\mathrm{a}}$} & \multicolumn{2}{|c|}{ NNLS algorithm } \\
\hline & & & & Out of total & Out of rigid Id. & & Out of total & Out of right Id. \\
\hline \multirow[t]{4}{*}{$N=150$} & $\sigma_{e}^{2}=1000$ & 1 & 946 & 8 & 1 & 580 & 8 & 1 \\
\hline & $\sigma_{e}^{2}=5000$ & 0 & 911 & 13 & 0 & 738 & 13 & 0 \\
\hline & $\sigma_{e}^{2}=10000$ & 1 & 879 & 33 & 2 & 746 & 33 & 2 \\
\hline & $\sigma_{e}^{2}=50000$ & 7 & 641 & 183 & 6 & 577 & 184 & 4 \\
\hline \multirow[t]{4}{*}{$N=300$} & $\sigma_{e}^{2}=1000$ & 1 & 982 & 4 & 0 & 663 & 4 & 0 \\
\hline & $\sigma_{e}^{2}=5000$ & 0 & 977 & 4 & 0 & 819 & 4 & 0 \\
\hline & $\sigma_{e}^{e}=10000$ & 0 & 957 & 5 & 0 & 831 & 5 & 0 \\
\hline & $\sigma_{e}^{2}=50000$ & 18 & 770 & 84 & 8 & 714 & 83 & 7 \\
\hline \multirow[t]{4}{*}{$N=450$} & $\sigma_{e}^{2}=1000$ & 0 & 996 & 1 & 0 & 620 & 1 & 0 \\
\hline & $\sigma_{e}^{2}=5000$ & 0 & 994 & 0 & 0 & 841 & 0 & 0 \\
\hline & $\sigma_{e}^{e}=10000$ & 0 & 990 & 0 & 0 & 884 & 0 & 0 \\
\hline & $\sigma_{e}^{2}=50000$ & 21 & 864 & 35 & 12 & 785 & 35 & 11 \\
\hline \multirow[t]{4}{*}{$N=600$} & $\sigma_{e}^{2}=1000$ & 0 & 998 & 0 & 0 & 636 & 0 & 0 \\
\hline & $\sigma_{e}^{e}=5000$ & 0 & 997 & 0 & 0 & 867 & 0 & 0 \\
\hline & $\sigma_{e}^{2}=10000$ & 0 & 990 & 0 & 0 & 906 & 0 & 0 \\
\hline & $\sigma_{e}^{2}=50000$ & 24 & 881 & 31 & 13 & 801 & 30 & 12 \\
\hline
\end{tabular}

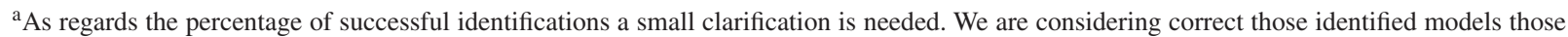
whose seven components coincide with the simulated ones. So those cases that we have labelled as "incorrect identifications" generally differ very little from the true model. Typically, only one out of the seven components is slightly different. Since correct identification of the whole model requires correct identification of eight roots, we can compute the percentage of the 128000 roots $(4$ samples sizes $\times 4$ noise levels $\times 1000$ replications $\times 8$ roots) that have been incorrectly identified. Such percentage is $1.2 \%$ in the case of "restricted identification", and $2.2 \%$ in the "unrestricted identification" case.

as the biggest integer index that verify $j<\operatorname{cograde}(b) \Rightarrow b_{j}=0$, we can define the inverse sequence of a non-null sequence $b$ with cograde $(b)=k$ as

$$
\left(b_{j}\right)^{-1} \equiv\left(\frac{1}{b}\right)_{j} \equiv \begin{cases}0 & \text { if } j<-k \\ \frac{1}{b_{k}} & \text { if } j=-k \\ \frac{-1}{b_{k}} \sum_{r=-k}^{j-1} a_{r} b_{j+k-r} & \text { if } j>-k\end{cases}
$$

(for more details see Bujosa et al., 2002).

\section{A.4. Propositions}

Proposition 1. For each $0<\omega_{j}<\pi$, there is a sequence $\Lambda_{s} p_{j}(L) \in \mathbb{C}(z)$ whose extended Fourier transform is the pseudo-spectrum $f_{s} p_{j}(\omega)$ of Eq. (9),

$$
\begin{aligned}
& \Lambda_{s} p_{j}(z) \\
& \quad=\sigma_{j}^{2} \frac{\left\{1+2 \alpha_{j} \beta_{j}+\alpha_{j}^{2}+\beta_{j}^{2}+\alpha_{j}^{2} \beta_{j}^{2}\right\}-\left\{\alpha_{j}+\beta_{j}+\alpha_{j} \beta_{j}^{2}+\alpha_{j}^{2} \beta_{j} \cos \left(\omega_{j}\right)\right\}\left(z+z^{-1}\right)+\left\{\alpha_{j} \beta_{j} \cos \left(2 \omega_{j}\right)\right\}\left(z^{2}+z^{-2}\right)}{\varphi_{j}(z) * \varphi_{j}\left(z^{-1}\right)} \longrightarrow,
\end{aligned}
$$

where

$$
\varphi_{j}(z)=\left[1-\left\{2\left(\alpha_{j}+\beta_{j}\right) \cos \omega_{j}\right\} z+\left\{\alpha_{j}^{2}+\beta_{j}^{2}+4 \alpha_{j} \beta_{j} \cos ^{2}\left(\omega_{j}\right)\right\} z^{2}-\left\{2\left(\alpha_{j} \beta_{j}^{2}+\alpha_{j}^{2} \beta_{j}\right) \cos \left(\omega_{j}\right)\right\} z^{3}+\left\{\alpha_{j}^{2} \beta_{j}^{2}\right\} z^{4}\right] .
$$


Table A2

Estimation with no identification. Estimated variances

Noise level

Sample size N

\begin{tabular}{llll}
\hline 150 & 300 & 450 & 600
\end{tabular}

\begin{tabular}{|c|c|c|c|c|c|}
\hline & $\sigma_{e}^{2}$ & & & & \\
\hline \multirow[t]{2}{*}{1000} & Median & 968 & 977 & 904 & 946 \\
\hline & IQR & 827 & 689 & 507 & 473 \\
\hline \multirow[t]{2}{*}{5000} & Median & 4279 & 4688 & 4676 & 4789 \\
\hline & IQR & 2257 & 1653 & 1229 & 1144 \\
\hline \multirow[t]{2}{*}{10000} & Median & 8548 & 9417 & 9507 & 9607 \\
\hline & IQR & 3967 & 2918 & 2244 & 1902 \\
\hline \multirow[t]{3}{*}{50000} & Median & 43665 & 46971 & 47570 & 48059 \\
\hline & IQR & 18779 & 12629 & 9648 & 8312 \\
\hline & $\sigma_{T}^{2}=\mathbf{5}$ & & & & \\
\hline \multirow[t]{2}{*}{1000} & Median & 4.4 & 4.7 & 4.9 & 4.8 \\
\hline & IQR & 3.7 & 2.5 & 2.0 & 1.8 \\
\hline \multirow[t]{2}{*}{5000} & Median & 4.8 & 5.0 & 5.1 & 5.0 \\
\hline & IQR & 4.6 & 2.9 & 2.2 & 2.2 \\
\hline \multirow[t]{2}{*}{10000} & Median & 5.1 & 5.1 & 5.2 & 5.2 \\
\hline & IQR & 5.0 & 3.0 & 2.4 & 2.2 \\
\hline \multirow[t]{3}{*}{50000} & Median & 8.3 & 6.8 & 6.2 & 5.8 \\
\hline & IQR & 8.7 & 4.9 & 4.1 & 3.5 \\
\hline & $\sigma_{S_{12}}^{2}=\mathbf{5 0}$ & & & & \\
\hline \multirow[t]{2}{*}{1000} & Median & 47.7 & 49.3 & 51.5 & 50.7 \\
\hline & IQR & 37.2 & 25.3 & 21.2 & 17.6 \\
\hline \multirow[t]{2}{*}{5000} & Median & 60.5 & 58.7 & 58.5 & 57.2 \\
\hline & IQR & 52.7 & 35.6 & 29.1 & 24.2 \\
\hline \multirow[t]{2}{*}{10000} & Median & 79.0 & 71.0 & 67.0 & 64.5 \\
\hline & IQR & 75.7 & 50.8 & 43.0 & 34.8 \\
\hline \multirow[t]{3}{*}{50000} & Median & 211.4 & 163.8 & 131.4 & 115.8 \\
\hline & IQR & 241.5 & 157.0 & 134.1 & 108.3 \\
\hline & $\sigma_{S_{6}}^{2}=\mathbf{5 0}$ & & & & \\
\hline \multirow[t]{2}{*}{1000} & Median & 46.9 & 49.6 & 51.4 & 51.3 \\
\hline & IQR & 35.3 & 23.3 & 19.4 & 16.8 \\
\hline \multirow[t]{2}{*}{5000} & Median & 62.6 & 57.8 & 58.9 & 56.1 \\
\hline & IQR & 53.4 & 34.5 & 30.3 & 25.9 \\
\hline \multirow[t]{2}{*}{10000} & Median & 78.9 & 66.4 & 66.3 & 62.0 \\
\hline & IQR & 73.3 & 45.7 & 39.2 & 33.2 \\
\hline \multirow[t]{3}{*}{50000} & Median & 208.9 & 144.4 & 120.7 & 109.8 \\
\hline & IQR & 242.7 & 143.4 & 124.3 & 104.0 \\
\hline & $\sigma_{S_{4}}^{2}=\mathbf{5 0}$ & & & & \\
\hline \multirow[t]{2}{*}{1000} & Median & 46.8 & 50.2 & 51.1 & 51.7 \\
\hline & IQR & 34.3 & 24.3 & 18.9 & 17.2 \\
\hline \multirow[t]{2}{*}{5000} & Median & 61.6 & 59.5 & 58.7 & 56.6 \\
\hline & IQR & 50.9 & 36.1 & 28.5 & 27.3 \\
\hline \multirow[t]{2}{*}{10000} & Median & 80.3 & 69.1 & 64.8 & 62.4 \\
\hline & IQR & 71.2 & 49.5 & 38.8 & 34.7 \\
\hline \multirow[t]{2}{*}{50000} & Median & 211.0 & 149.6 & 126.7 & 106.0 \\
\hline & IQR & 225.1 & 145.2 & 119.5 & 117.6 \\
\hline
\end{tabular}


Table A2 (Continued)

\begin{tabular}{|c|c|c|c|c|c|}
\hline \multirow[t]{2}{*}{ Noise level } & & \multicolumn{4}{|c|}{ Sample size N } \\
\hline & & 150 & 300 & 450 & 600 \\
\hline & $\sigma_{S_{3}}^{2}=\mathbf{5 0}$ & & & & \\
\hline \multirow[t]{2}{*}{1000} & Median & 45.3 & 48.2 & 52.3 & 51.0 \\
\hline & IQR & 32.0 & 23.6 & 18.8 & 18.0 \\
\hline \multirow[t]{2}{*}{5000} & Median & 59.8 & 58.4 & 58.7 & 56.3 \\
\hline & IQR & 50.4 & 35.2 & 28.6 & 24.9 \\
\hline \multirow[t]{2}{*}{10000} & Median & 75.7 & 67.6 & 65.4 & 60.6 \\
\hline & IQR & 67.7 & 49.0 & 37.6 & 32.4 \\
\hline \multirow[t]{3}{*}{50000} & Median & 200.2 & 143.6 & 121.1 & 106.4 \\
\hline & IQR & 239.5 & 156.7 & 113.3 & 106.8 \\
\hline & $\sigma_{S_{2.4}}^{2}=\mathbf{5 0}$ & & & & \\
\hline \multirow[t]{2}{*}{1000} & Median & 45.7 & 48.5 & 52.0 & 51.0 \\
\hline & IQR & 32.1 & 24.5 & 20.1 & 17.4 \\
\hline \multirow[t]{2}{*}{5000} & Median & 60.6 & 57.8 & 59.5 & 56.7 \\
\hline & IQR & 49.8 & 37.6 & 28.6 & 24.4 \\
\hline \multirow[t]{2}{*}{10000} & Median & 77.8 & 65.9 & 66.0 & 60.9 \\
\hline & $\mathrm{IQR}$ & 69.1 & 49.1 & 41.1 & 33.7 \\
\hline \multirow[t]{3}{*}{50000} & Median & 199.6 & 143.4 & 126.5 & 104.9 \\
\hline & IQR & 212.1 & 140.8 & 121.1 & 103.5 \\
\hline & $\sigma_{S_{2}}^{2}=\mathbf{5 0}$ & & & & \\
\hline \multirow[t]{2}{*}{1000} & Median & 40.2 & 47.9 & 49.2 & 49.8 \\
\hline & IQR & 39.2 & 32.2 & 26.5 & 23.9 \\
\hline \multirow[t]{2}{*}{5000} & Median & 52.6 & 53.1 & 53.4 & 53.7 \\
\hline & $\mathrm{IQR}$ & 53.0 & 40.2 & 32.6 & 28.5 \\
\hline \multirow[t]{2}{*}{10000} & Median & 62.9 & 58.5 & 57.7 & 57.2 \\
\hline & IQR & 66.8 & 49.9 & 41.2 & 35.0 \\
\hline \multirow[t]{2}{*}{50000} & Median & 139.7 & 110.5 & 97.2 & 86.6 \\
\hline & IQR & 161.8 & 121.4 & 92.7 & 81.4 \\
\hline
\end{tabular}

Sample size: N, noise level: $\sigma_{e}^{2}$, true value in frame box. For the variance of the irregular component, the noise level is the true value.

Proof. We proceed backwards. Substituting $2 \cos x$ by $\mathrm{e}^{\mathrm{i} x}+\mathrm{e}^{-\mathrm{i} x}$ in (9), factorizing, and then substituting $\mathrm{e}^{-\mathrm{i} x}$ by $z$, we obtain the sequence $\Lambda_{s} p_{j}(L)$

$$
\begin{aligned}
& \Lambda_{s} p_{j}(z) \\
& =\sigma_{j}^{2} / 2 \cdot \frac{\left[1-\alpha_{j} \mathrm{e}^{\overline{\mathrm{i} \omega_{j}}} / z\right]\left[1-\beta_{j} \mathrm{e}^{\overline{\mathrm{i} \omega_{j}}} / z\right]\left[1-\alpha_{j} \mathrm{e}^{\mathrm{i} \omega_{j}} z\right]\left[1-\beta_{j} \mathrm{e}^{\mathrm{i} \omega_{j}} z\right]+\left[1-\alpha_{j} \mathrm{e}^{\mathrm{i} \omega_{j}} / z\right]\left[1-\beta_{j} \mathrm{e}^{\mathrm{i} \omega_{j}} / z\right]\left[1-\alpha_{j} \mathrm{e}^{\overline{\mathrm{i} \omega j} j} z\right]\left[1-\beta_{j} \mathrm{e}^{\overline{\mathrm{i} \omega_{j}}} z\right]}{\left[1-\alpha_{j} \mathrm{e}^{\mathrm{i} \omega_{j}} / z\right]\left[1-\beta_{j} \mathrm{e}^{\mathrm{i} \omega_{j}} / z\right]\left[1-\alpha_{j} \mathrm{e}^{\mathrm{i} \omega_{j}} z\right]\left[1-\beta_{j} \mathrm{e}^{\mathrm{i} \omega_{j}} z\right]+\left[1-\alpha_{j} \mathrm{e}^{\mathrm{i} \omega_{j}} / z\right]\left[1-\beta_{j} \mathrm{e}^{\mathrm{i} \omega_{j}} / z\right]\left[1-\alpha_{j} \mathrm{e}^{\mathrm{i} \omega_{j}} z\right]\left[1-\beta_{j} \mathrm{e}^{\mathrm{i} \omega_{j}} z\right]} .
\end{aligned}
$$

Operating and substituting $\mathrm{e}^{\mathrm{i} x}+\mathrm{e}^{-\mathrm{i} x}$ by $2 \cos x$, we finally obtain Eq. (A.1).

Proposition 2. For each $0<\omega_{j}<\pi$, there is an ARMA model whose pseudo-covariance generating function is the sequence $\Lambda_{s} p_{j}(L) \in \mathbb{C}(z)$ from Eq. (A.1) of Proposition 1 .

Proof. The proof for the AR part is straight forward from Eq. (A.2) and is simply

$$
\varphi_{j}(L)=\phi_{j}^{\alpha}(L) * \phi_{j}^{\beta}(L)
$$


Table A3

Estimation with no identification. Estimated noise variance ration NVR (true value in bold)

\begin{tabular}{|c|c|c|c|c|c|}
\hline \multicolumn{2}{|c|}{ True value } & \multicolumn{4}{|c|}{ Sample size N } \\
\hline & & 150 & 300 & 450 & 600 \\
\hline & \multicolumn{5}{|l|}{$\widehat{N V R_{T}}$} \\
\hline \multirow[t]{2}{*}{5} & Median & 4.65 & 5.06 & 5.48 & 5.18 \\
\hline & IQR & 5.84 & 4.79 & 3.98 & 3.41 \\
\hline \multirow[t]{2}{*}{1} & Median & 1.11 & 1.09 & 1.10 & 1.03 \\
\hline & IQR & 1.25 & 0.71 & 0.54 & 0.51 \\
\hline \multirow[t]{2}{*}{0.5} & Median & 0.60 & 0.55 & 0.56 & 0.53 \\
\hline & IQR & 0.64 & 0.36 & 0.28 & 0.27 \\
\hline \multirow[t]{3}{*}{0.1} & Median & 0.19 & 0.15 & 0.13 & 0.12 \\
\hline & IQR & 0.23 & 0.11 & 0.09 & 0.08 \\
\hline & $N{\widehat{V R_{S}}}_{12}$ & & & & \\
\hline \multirow[t]{2}{*}{50} & Median & 49.09 & 52.21 & 57.25 & 54.23 \\
\hline & IQR & 61.07 & 51.19 & 44.61 & 34.63 \\
\hline \multirow[t]{2}{*}{10} & Median & 14.27 & 12.66 & 12.63 & 11.79 \\
\hline & IQR & 15.99 & 9.89 & 7.34 & 5.88 \\
\hline \multirow[t]{2}{*}{5} & Median & 9.37 & 7.52 & 7.19 & 6.56 \\
\hline & IQR & 9.68 & 6.09 & 4.88 & 3.98 \\
\hline \multirow[t]{3}{*}{1} & Median & 4.71 & 3.44 & 2.73 & 2.35 \\
\hline & IQR & 6.07 & 3.56 & 2.90 & 2.45 \\
\hline & $\widehat{N V R_{S_{6}}}$ & & & & \\
\hline \multirow[t]{2}{*}{50} & Median & 47.69 & 51.79 & 55.87 & 53.98 \\
\hline & IQR & 61.28 & 51.79 & 46.87 & 35.93 \\
\hline \multirow[t]{2}{*}{10} & Median & 15.00 & 12.27 & 12.43 & 11.70 \\
\hline & IQR & 15.84 & 9.03 & 7.35 & 6.33 \\
\hline \multirow[t]{2}{*}{5} & Median & 9.34 & 6.96 & 6.95 & 6.41 \\
\hline & IQR & 10.44 & 5.50 & 4.67 & 3.98 \\
\hline \multirow[t]{3}{*}{1} & Median & 4.78 & 3.09 & 2.55 & 2.25 \\
\hline & IQR & 5.74 & 3.16 & 2.68 & 2.30 \\
\hline & $\widehat{N V R_{S_{4}}}$ & & & & \\
\hline \multirow[t]{2}{*}{50} & Median & 48.77 & 53.00 & 55.99 & 55.36 \\
\hline & IQR & 66.51 & 48.63 & 46.72 & 38.89 \\
\hline \multirow[t]{2}{*}{10} & Median & 14.96 & 12.42 & 12.60 & 11.83 \\
\hline & IQR & 16.15 & 9.37 & 7.35 & 6.28 \\
\hline \multirow[t]{2}{*}{5} & Median & 9.16 & 7.27 & 7.00 & 6.47 \\
\hline & IQR & 10.52 & 5.76 & 4.56 & 3.88 \\
\hline \multirow[t]{3}{*}{1} & Median & 4.87 & 3.12 & 2.66 & 2.20 \\
\hline & IQR & 6.00 & 3.39 & 2.64 & 2.46 \\
\hline & $\widehat{N V R_{S_{3}}}$ & & & & \\
\hline \multirow[t]{2}{*}{50} & Median & 48.12 & 51.32 & 57.83 & 54.18 \\
\hline & IQR & 64.40 & 52.54 & 46.98 & 41.03 \\
\hline \multirow[t]{2}{*}{10} & Median & 14.18 & 12.41 & 12.37 & 11.77 \\
\hline & IQR & 14.59 & 9.67 & 7.24 & 6.31 \\
\hline \multirow[t]{2}{*}{5} & Median & 8.83 & 7.03 & 6.85 & 6.26 \\
\hline & IQR & 9.56 & 6.16 & 4.69 & 3.86 \\
\hline \multirow[t]{2}{*}{1} & Median & 4.48 & 3.05 & 2.54 & 2.20 \\
\hline & IQR & 5.71 & 3.61 & 2.62 & 2.34 \\
\hline
\end{tabular}


Table A3 (Continued)

\begin{tabular}{|c|c|c|c|c|c|}
\hline \multicolumn{2}{|c|}{ True value } & \multicolumn{4}{|c|}{ Sample size N } \\
\hline & & 150 & 300 & 450 & 600 \\
\hline & \multicolumn{5}{|l|}{$\sqrt{N R_{S_{2}}}$} \\
\hline \multirow[t]{2}{*}{50} & Median & 42.85 & 51.21 & 53.43 & 51.89 \\
\hline & IQR & 67.03 & 63.88 & 59.99 & 46.73 \\
\hline \multirow[t]{2}{*}{10} & Median & 11.63 & 11.19 & 11.06 & 11.06 \\
\hline & IQR & 15.61 & 10.88 & 8.52 & 7.25 \\
\hline \multirow[t]{2}{*}{5} & Median & 6.97 & 6.09 & 5.97 & 5.96 \\
\hline & IQR & 8.60 & 5.96 & 4.88 & 4.09 \\
\hline \multirow[t]{3}{*}{1} & Median & 3.12 & 2.35 & 1.98 & 1.76 \\
\hline & IQR & 4.07 & 2.80 & 2.11 & 1.76 \\
\hline & $N \widehat{V R_{S_{2.4}}}$ & & & & \\
\hline \multirow[t]{2}{*}{50} & Median & 46.97 & 50.43 & 58.60 & 54.62 \\
\hline & IQR & 65.01 & 55.43 & 44.11 & 39.93 \\
\hline \multirow[t]{2}{*}{10} & Median & 13.90 & 12.27 & 12.66 & 11.80 \\
\hline & IQR & 15.15 & 10.25 & 8.14 & 6.53 \\
\hline \multirow[t]{2}{*}{5} & Median & 8.93 & 6.87 & 6.89 & 6.37 \\
\hline & IQR & 9.34 & 6.42 & 5.07 & 4.12 \\
\hline \multirow[t]{2}{*}{1} & Median & 4.58 & 3.00 & 2.61 & 2.19 \\
\hline & IQR & 5.85 & 3.26 & 2.71 & 2.30 \\
\hline
\end{tabular}

$\mathrm{N}$ is the sample size. IRQ means inter-quartile range $(N V R$ and statistics $\times 1000)$. I.e., " $N V R=5$ " means $N V R=0.005$ and "median $=4.51$ " means median $=0.00451$.

where

$$
\begin{aligned}
& \phi_{j}^{\alpha}(L)=\left[1-2 \alpha_{j} \cos \left(\omega_{j}\right) L+\alpha_{j}^{2} L^{2}\right]=\left[1-\alpha_{j} \mathrm{e}^{\mathrm{i} \omega_{j}} L\right]\left[1-\alpha_{j} \mathrm{e}^{-\mathrm{i} \omega_{j}} L\right] \\
& \phi_{j}^{\beta}(L)=\left[1-2 \beta_{j} \cos \left(\omega_{j}\right) L+\beta_{j}^{2} L^{2}\right]=\left[1-\beta_{j} \mathrm{e}^{\mathrm{i} \omega_{j}} L\right]\left[1-\beta_{j} \mathrm{e}^{-\mathrm{i} \omega_{j}} L\right] .
\end{aligned}
$$

The proof for the moving average part is much more tedious. We search the moving average (MA) polynomial $\theta_{j}(L)$ such that $\theta_{j}(z) \theta_{j}\left(z^{-1}\right)$ equals the numerator in (A.3). Substituting $z$ by $L, 1 / z$ by $F$, and operating on the numerator in (A.3) we can obtain the expression

$$
\begin{aligned}
& \left(1-\alpha_{j}^{-1} \mathrm{e}^{\mathrm{i} \omega_{j}} L\right)\left(1-\beta_{j}^{-1} \mathrm{e}^{\mathrm{i} \omega_{j}} L\right)\left(1-\alpha_{j} \mathrm{e}^{\mathrm{i} \omega_{j}} L\right)\left(1-\beta_{j} \mathrm{e}^{\mathrm{i} \omega_{j}} L\right)\left(\alpha_{j} \beta_{j} \mathrm{e}^{\overline{2 \mathrm{i} \omega_{j}}}\right) F^{2} \\
& \quad+\left(1-\alpha_{j}^{-1} \mathrm{e}^{\overline{\mathrm{i} \omega_{j}}} L\right)\left(1-\beta_{j}^{-1} \mathrm{e}^{\overline{\mathrm{i} \omega \omega_{j}}} L\right)\left(1-\alpha_{j} \mathrm{e}^{\overline{\mathrm{i} \omega_{j}}} L\right)\left(1-\beta_{j} \mathrm{e}^{\overline{\mathrm{i} \omega_{j}}} L\right)\left(\alpha_{j} \beta_{j} \mathrm{e}^{2 \mathrm{i} \omega_{j}}\right) F^{2} .
\end{aligned}
$$

It is not difficult to prove that if $x$ is a root of (A.5) then, $1 / x$ is also a root. It follows that $\theta_{j}(z) \theta_{j}\left(z^{-1}\right)$ can be divided by

$$
(1-\gamma L)\left(1-\gamma^{-1} L\right)(1-\eta L)\left(1-\eta^{-1} L\right)
$$

Some characteristics of $\gamma$ and $\eta$ are known. Because the pseudo-spectra of the DHR models are positive definite none of the MA roots has unit modulus; and because $\theta_{j}(z)$ is real, if $\gamma$ is not real and $|\gamma| \neq 1$, then $\eta=\bar{\gamma}$. So, two scenarios are possible. In the first one, there are two real roots with modulus greater than one and their inverses, in the second one, there are four complex roots, and for each one of them there are its inverse, its complex pair, and the inverse of its complex pair.

We need to find the constant $\lambda$ and the coefficients $\gamma$ and $\eta$ that verify that $\theta_{j}(L) \theta_{j}(F)$ equals (A.5), and

$$
\theta_{j}(L) \theta_{j}(F)=\lambda F^{2}(1-\gamma L)\left(1-\gamma^{-1} L\right)(1-\eta L)\left(1-\eta^{-1} L\right) .
$$


Table A4

Estimation with no identification. Results using CAPTAIN: estimated noise variance ratio NVR (true value in bold)

\begin{tabular}{|c|c|c|c|c|c|}
\hline \multirow[t]{2}{*}{ True value } & & \multicolumn{4}{|c|}{ Sample size N } \\
\hline & & 150 & 300 & 450 & 600 \\
\hline & $\widehat{N V R_{T}}$ & & & & \\
\hline \multirow[t]{2}{*}{5} & Median & 1.58 & 1.85 & 1.92 & 1.98 \\
\hline & IQR & 1.35 & 0.89 & 0.75 & 0.66 \\
\hline \multirow[t]{2}{*}{1} & Median & 0.80 & 1.09 & 1.13 & 1.13 \\
\hline & IQR & 0.99 & 0.65 & 0.50 & 0.44 \\
\hline \multirow[t]{2}{*}{0.5} & Median & 0.53 & 0.73 & 0.77 & 0.79 \\
\hline & IQR & 0.70 & 0.48 & 0.38 & 0.32 \\
\hline \multirow[t]{3}{*}{0.1} & Median & 0.09 & 0.29 & 0.33 & 0.36 \\
\hline & IQR & 0.28 & 0.26 & 0.18 & 0.16 \\
\hline & $N{\widehat{V R_{S}}}_{12}$ & & & & \\
\hline \multirow[t]{2}{*}{50} & Median & 12.92 & 11.08 & 10.48 & 10.20 \\
\hline & IQR & 6.94 & 3.83 & 2.94 & 2.49 \\
\hline \multirow[t]{2}{*}{10} & Median & 11.67 & 9.29 & 9.12 & 8.56 \\
\hline & IQR & 7.49 & 3.85 & 3.09 & 3.08 \\
\hline \multirow[t]{2}{*}{5} & Median & 11.17 & 8.85 & 8.09 & 6.93 \\
\hline & IQR & 8.68 & 4.54 & 3.73 & 3.11 \\
\hline \multirow[t]{3}{*}{1} & Median & 10.69 & 7.53 & 6.44 & 6.07 \\
\hline & IQR & 10.68 & 5.27 & 3.65 & 2.59 \\
\hline & $\sqrt{N V R_{S_{6}}}$ & & & & \\
\hline \multirow[t]{2}{*}{50} & Median & 10.28 & 10.71 & 10.48 & 9.99 \\
\hline & IQR & 5.67 & 4.95 & 4.53 & 3.68 \\
\hline \multirow[t]{2}{*}{10} & Median & 10.18 & 7.88 & 7.75 & 7.48 \\
\hline & IQR & 6.36 & 3.90 & 2.76 & 2.40 \\
\hline \multirow[t]{2}{*}{5} & Median & 9.70 & 7.25 & 7.05 & 6.62 \\
\hline & IQR & 6.83 & 3.71 & 3.06 & 2.40 \\
\hline \multirow[t]{3}{*}{1} & Median & 9.49 & 6.47 & 6.20 & 5.95 \\
\hline & IQR & 8.63 & 4.38 & 3.44 & 2.59 \\
\hline & $\widehat{N V R}_{S_{4}}$ & & & & \\
\hline \multirow[t]{2}{*}{50} & Median & 12.32 & 11.36 & 10.43 & 9.89 \\
\hline & IQR & 6.68 & 4.74 & 3.79 & 3.24 \\
\hline \multirow[t]{2}{*}{10} & Median & 10.46 & 7.98 & 7.61 & 7.53 \\
\hline & IQR & 7.07 & 3.85 & 2.91 & 2.54 \\
\hline \multirow[t]{2}{*}{5} & Median & 9.82 & 7.65 & 7.12 & 6.76 \\
\hline & IQR & 6.87 & 3.92 & 2.94 & 2.63 \\
\hline \multirow[t]{3}{*}{1} & Median & 9.31 & 6.90 & 6.29 & 5.97 \\
\hline & IQR & 8.21 & 4.57 & 3.39 & 2.77 \\
\hline & $\widehat{N V R}_{S_{3}}$ & & & & \\
\hline \multirow[t]{2}{*}{50} & Median & 11.03 & 11.27 & 10.68 & 9.84 \\
\hline & IQR & 5.62 & 4.58 & 4.21 & 3.44 \\
\hline \multirow[t]{2}{*}{10} & Median & 9.89 & 8.08 & 7.77 & 7.41 \\
\hline & IQR & 6.89 & 3.68 & 2.70 & 2.37 \\
\hline \multirow[t]{2}{*}{5} & Median & 9.33 & 7.67 & 7.31 & 6.72 \\
\hline & IQR & 7.06 & 3.80 & 3.05 & 2.55 \\
\hline \multirow[t]{2}{*}{1} & Median & 8.92 & 7.18 & 6.25 & 5.94 \\
\hline & IQR & 7.76 & 4.52 & 3.36 & 2.81 \\
\hline
\end{tabular}


Table A4 (Continued)

\begin{tabular}{|c|c|c|c|c|c|}
\hline \multirow[t]{2}{*}{ True value } & & \multicolumn{4}{|c|}{ Sample size N } \\
\hline & & 150 & 300 & 450 & 600 \\
\hline & $N \widehat{V R_{S}}{ }_{2.4}$ & & & & \\
\hline \multirow[t]{2}{*}{50} & Median & 12.31 & 11.40 & 10.72 & 10.01 \\
\hline & IQR & 5.85 & 4.43 & 3.96 & 3.31 \\
\hline \multirow[t]{2}{*}{10} & Median & 11.03 & 8.25 & 7.99 & 7.63 \\
\hline & IQR & 7.58 & 3.77 & 2.71 & 2.31 \\
\hline \multirow[t]{2}{*}{5} & Median & 9.82 & 7.71 & 7.42 & 6.80 \\
\hline & IQR & 7.65 & 3.77 & 3.05 & 2.39 \\
\hline \multirow[t]{3}{*}{1} & Median & 9.16 & 6.89 & 6.32 & 6.10 \\
\hline & IQR & 8.59 & 4.28 & 3.30 & 2.91 \\
\hline & $\sqrt{N V R_{S_{2}}}$ & & & & \\
\hline \multirow[t]{2}{*}{50} & Median & 8.23 & 9.02 & 8.97 & 8.94 \\
\hline & IQR & 7.11 & 4.83 & 4.07 & 3.59 \\
\hline \multirow[t]{2}{*}{10} & Median & 6.25 & 5.81 & 5.73 & 5.98 \\
\hline & IQR & 5.93 & 4.21 & 3.27 & 2.89 \\
\hline \multirow[t]{2}{*}{5} & Median & 5.32 & 4.79 & 4.74 & 4.88 \\
\hline & IQR & 5.59 & 3.68 & 3.07 & 2.42 \\
\hline \multirow[t]{2}{*}{1} & Median & 4.79 & 3.53 & 3.26 & 3.35 \\
\hline & IQR & 5.96 & 3.44 & 2.62 & 2.18 \\
\hline
\end{tabular}

$\mathrm{N}$ is the sample size. IRQ means inter-quartile range $(N V R$ and statistics $\times 1000)$. I.e., " $N V R=5$ " means $N V R=0.005$ and "median $=4.51$ " means median $=0.00451$.

Therefore, the general form of the MA should be

$$
\theta_{j}(L)=\sqrt{\lambda}\left(1-\gamma_{j}^{\star} L\right)\left(1-\eta_{j}^{\star} L\right),
$$

where $\gamma_{j}^{\star}$ and $\eta_{j}^{\star}$ are inside the unit circle, and $\lambda$ is a constant.

On the one hand ignoring $\lambda F^{2}$ in (A.6), and operating, it can be obtained the polynomial

$$
\left(L^{2}-\left(\gamma+\gamma^{-1}\right) L+1\right)\left(L^{2}-\left(\eta+\eta^{-1}\right) L+1\right),
$$

or $\left(L^{2}+\delta L+1\right)\left(L^{2}+\rho L+1\right)$, where $\delta=-\left(\gamma+\gamma^{-1}\right)$ and $\rho=-\left(\eta+\eta^{-1}\right)$. This polynomial is equivalent to:

$$
L^{4}+(\delta+\rho) L^{3}+(\delta \rho+2) L^{2}+(\delta+\rho) L+1,
$$

where $\delta$ and $\rho$ verify

$$
\gamma^{2}+\delta \gamma+1=0, \quad \eta^{2}+\rho \eta+1=0 .
$$

If the fourth order polynomial $a L^{4}+b L^{3}+c L^{2}+d L+e$ is divided by $L^{4}+(\delta+\rho) L^{3}+(\delta \rho+2) L^{2}+(\delta+\rho) L+1$ we obtained

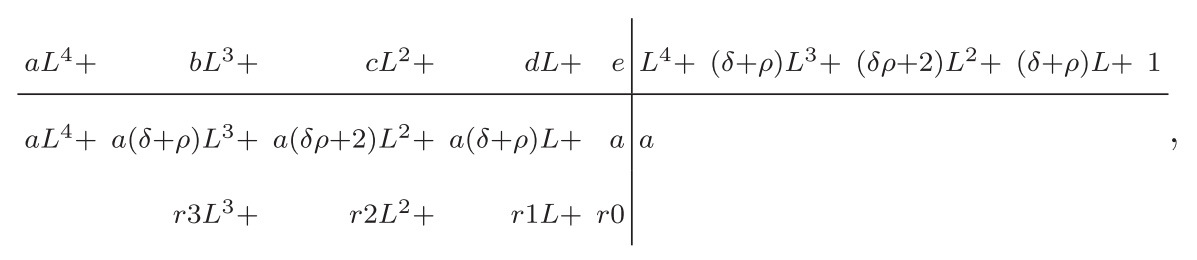

where $r_{3}=b-a(\delta+\rho) ; r_{2}=c-a(\delta \rho+2) ; r_{1}=d-a(\delta+\rho) ; r_{0}=e-a$. 
Table A5

Restricted identification. Estimated variances

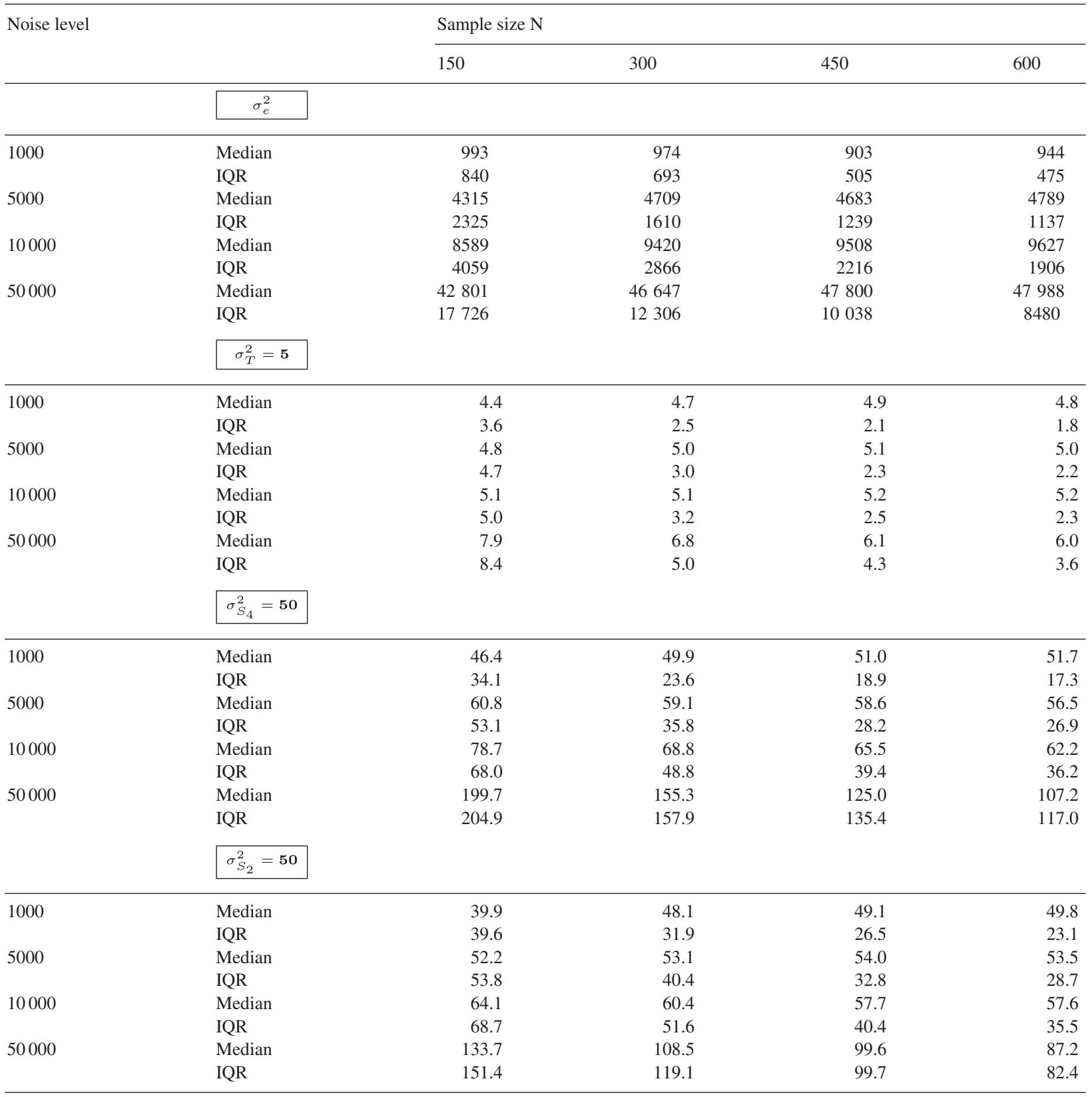

Sample size: N, noise level: $\sigma_{e}^{2}$, true value in frame box. For the variance of the irregular component, the noise level is the true value.

Since a necessary condition for the remainder to be zero is

$$
\begin{aligned}
& 0=r_{3}=b-a(\delta+\rho) \\
& 0=r_{2}=c-a(\delta \rho+2),
\end{aligned}
$$

$\delta$ and $\rho$ should verify

$$
\delta=\frac{-b \pm \sqrt{b^{2}+4 a(2 a-c)}}{-2 a}, \quad \rho=\frac{b}{a}-\delta .
$$


Table A6

Restricted identification. Estimated noise variance ratio $N V R$ (true value in bold)

\begin{tabular}{|c|c|c|c|c|c|}
\hline \multicolumn{2}{|c|}{ True value } & \multicolumn{4}{|c|}{ Sample size N } \\
\hline & & \multirow[t]{2}{*}{150} & \multirow[t]{2}{*}{300} & \multirow[t]{2}{*}{450} & \multirow[t]{2}{*}{600} \\
\hline & $\widehat{N V R_{T}}$ & & & & \\
\hline \multirow[t]{2}{*}{5} & Median & 4.38 & 5.04 & 5.46 & 5.16 \\
\hline & IQR & 5.55 & 4.76 & 3.87 & 3.34 \\
\hline \multirow[t]{2}{*}{1} & Median & 1.08 & 1.08 & 1.10 & 1.05 \\
\hline & IQR & 1.19 & 0.71 & 0.54 & 0.51 \\
\hline \multirow[t]{2}{*}{0.5} & Median & 0.59 & 0.57 & 0.55 & 0.53 \\
\hline & IQR & 0.63 & 0.37 & 0.28 & 0.27 \\
\hline \multirow[t]{3}{*}{0.1} & Median & 0.19 & 0.15 & 0.13 & 0.13 \\
\hline & IQR & 0.23 & 0.11 & 0.09 & 0.08 \\
\hline & $\widehat{N \widehat{N R}_{S_{4}}}$ & & & & \\
\hline \multirow[t]{2}{*}{50} & Median & 47.01 & 52.98 & 55.19 & 55.74 \\
\hline & IQR & 63.51 & 48.54 & 46.85 & 38.82 \\
\hline \multirow[t]{2}{*}{10} & Median & 14.28 & 12.38 & 12.66 & 11.83 \\
\hline & IQR & 16.00 & 9.56 & 7.17 & 6.41 \\
\hline \multirow[t]{2}{*}{5} & Median & 8.87 & 7.22 & 6.99 & 6.46 \\
\hline & IQR & 10.26 & 5.98 & 4.62 & 4.15 \\
\hline \multirow[t]{3}{*}{1} & Median & 4.48 & 3.21 & 2.65 & 2.24 \\
\hline & IQR & 5.48 & 3.53 & 2.89 & 2.53 \\
\hline & $\widehat{N V R_{S_{2}}}$ & & & & \\
\hline \multirow[t]{2}{*}{50} & Median & 41.52 & 50.62 & 52.92 & 51.81 \\
\hline & IQR & 65.28 & 63.99 & 59.65 & 46.55 \\
\hline \multirow[t]{2}{*}{10} & Median & 11.35 & 11.10 & 11.26 & 10.96 \\
\hline & IQR & 15.11 & 10.44 & 8.64 & 7.34 \\
\hline \multirow[t]{2}{*}{5} & Median & 7.03 & 6.27 & 5.99 & 6.03 \\
\hline & IQR & 9.22 & 5.96 & 4.82 & 4.15 \\
\hline \multirow[t]{2}{*}{1} & Median & 2.97 & 2.23 & 2.06 & 1.80 \\
\hline & IQR & 4.21 & 2.64 & 2.26 & 1.82 \\
\hline
\end{tabular}

$\mathrm{N}$ is the sample size. IRQ means inter-quartile range $(N V R$ and statistics $\times 1000)$. I.e., " $N V R=5$ " means $N V R=0.005$ and "median $=4.51$ " means median $=0.00451$.

On the other hand, the roots of Eq. (A.5) are the roots of

$$
\begin{aligned}
& \mathrm{e}^{-2 \mathrm{i} \omega_{j}}-(A+B) \mathrm{e}^{-\mathrm{i} \omega_{j}} L+(2+A \cdot B) L^{2}-(A+B) \mathrm{e}^{\mathrm{i} \omega_{j}} L^{3}+\mathrm{e}^{2 \mathrm{i} \omega_{j}} L^{4} \\
& \quad+\mathrm{e}^{2 \mathrm{i} \omega_{j}}-(A+B) \mathrm{e}^{\mathrm{i} \omega_{j}} L+(2+A \cdot B) L^{2}-(A+B) \mathrm{e}^{-\mathrm{i} \omega_{j}} L^{3}+\mathrm{e}^{-2 \mathrm{i} \omega_{j}} L^{4},
\end{aligned}
$$

where $A=\alpha_{j}+\alpha_{j}^{-1}$ and $B=\beta_{j}+\beta_{j}^{-1}$.

If we substitute $\mathrm{e}^{\mathrm{i} \omega_{j}}+\mathrm{e}^{-\mathrm{i} \omega_{j}}$ by $\Omega_{j}$ we can find that

$$
\underbrace{\left(\Omega_{j}^{2}-2\right)}_{e}-\underbrace{(A+B) \Omega_{j}}_{d} L+\underbrace{(4+2 A B)}_{c} L^{2}-\underbrace{(A+B) \Omega_{j}}_{b} L^{3}+\underbrace{\left(\Omega_{j}^{2}-2\right)}_{a} L^{4} .
$$

Therefore, $2 a-c=2\left(\Omega_{j}^{2}-2\right)-4-A B$, and $-b=-(A+B) \Omega_{j}$. Substituting in (A.9) we find that

$$
\delta=\frac{(A+B) \Omega_{j} \pm \sqrt{(A+B)^{2} \Omega_{j}^{2}+8\left(\Omega_{j}^{2}-2\right)\left(\Omega_{j}^{2}-4-(A B)\right)}}{-2\left(\Omega_{j}^{2}-2\right)} .
$$


Table A7

Unrestricted identification. Estimated variance

\begin{tabular}{|c|c|c|c|c|c|}
\hline \multicolumn{2}{|c|}{ Noise level } & \multicolumn{4}{|c|}{ Sample size N } \\
\hline & & \multirow[t]{2}{*}{150} & \multirow[t]{2}{*}{300} & \multirow[t]{2}{*}{450} & \multirow[t]{2}{*}{600} \\
\hline & $\sigma_{e}^{2}$ & & & & \\
\hline \multirow[t]{2}{*}{1000} & Median & 1364 & 1191 & 1091 & 1101 \\
\hline & IQR & 876 & 648 & 498 & 442 \\
\hline \multirow[t]{2}{*}{5000} & Median & 4600 & 4889 & 4870 & 4910 \\
\hline & IQR & 2242 & 1674 & 1276 & 1162 \\
\hline \multirow[t]{2}{*}{10000} & Median & 8912 & 9521 & 9508 & 9730 \\
\hline & IQR & 3938 & 2825 & 2206 & 1937 \\
\hline \multirow[t]{3}{*}{50000} & Median & 42285 & 46816 & 47874 & 48092 \\
\hline & IQR & 17278 & 12510 & 9907 & 8899 \\
\hline & $\sigma_{T}^{2}=5$ & & & & \\
\hline \multirow[t]{2}{*}{1000} & Median & 4.4 & 4.7 & 4.9 & 4.9 \\
\hline & IQR & 3.6 & 2.4 & 2.1 & 1.8 \\
\hline \multirow[t]{2}{*}{5000} & Median & 4.8 & 5.1 & 5.1 & 5.2 \\
\hline & IQR & 4.7 & 3.1 & 2.5 & 2.2 \\
\hline \multirow[t]{2}{*}{10000} & Median & 5.1 & 5.3 & 5.4 & 5.3 \\
\hline & IQR & 5.2 & 3.5 & 2.9 & 2.5 \\
\hline \multirow[t]{3}{*}{50000} & Median & 8.1 & 6.8 & 6.2 & 6.1 \\
\hline & IQR & 8.6 & 5.2 & 4.5 & 3.9 \\
\hline & $\sigma_{S_{4}}^{2}=50$ & & & & \\
\hline \multirow[t]{2}{*}{1000} & Median & 40.8 & 46.6 & 48.4 & 47.8 \\
\hline & IQR & 34.1 & 24.1 & 18.9 & 18.4 \\
\hline \multirow[t]{2}{*}{5000} & Median & 56.0 & 57.4 & 56.3 & 53.6 \\
\hline & IQR & 56.0 & 39.4 & 34.0 & 30.5 \\
\hline \multirow[t]{2}{*}{10000} & Median & 75.4 & 67.9 & 65.1 & 60.0 \\
\hline & IQR & 75.8 & 49.7 & 45.3 & 43.5 \\
\hline \multirow[t]{3}{*}{50000} & Median & 187.9 & 157.9 & 125.8 & 112.7 \\
\hline & IQR & 201.9 & 159.6 & 146.3 & 122.6 \\
\hline & $\sigma_{S_{2}}^{2}=50$ & & & & \\
\hline \multirow[t]{2}{*}{1000} & Median & 32.0 & 40.6 & 43.3 & 44.1 \\
\hline & IQR & 42.4 & 32.3 & 25.5 & 24.2 \\
\hline \multirow[t]{2}{*}{5000} & Median & 45.9 & 48.2 & 49.7 & 48.7 \\
\hline & IQR & 51.7 & 40.7 & 36.0 & 31.4 \\
\hline \multirow[t]{2}{*}{10000} & Median & 60.5 & 56.2 & 55.4 & 53.9 \\
\hline & IQR & 65.6 & 50.7 & 42.6 & 38.1 \\
\hline \multirow[t]{2}{*}{50000} & Median & 130.0 & 106.7 & 100.7 & 87.7 \\
\hline & IQR & 150.4 & 119.3 & 103.3 & 83.4 \\
\hline
\end{tabular}

Sample size: N, noise level: $\sigma_{e}^{2}$, true value in frame box. For the variance of the irregular component, the noise level is the true value.

Finally, using Eq. (A.8), we have found that

$$
\gamma=\frac{-\delta \pm \sqrt{\delta^{2}-4}}{2}, \quad \eta=\frac{-\rho \pm \sqrt{\rho^{2}-4}}{2}
$$


Table A8

Unrestricted identification. Estimated noise variance ratio $N V R$ (true value in bold)

\begin{tabular}{|c|c|c|c|c|c|}
\hline \multirow[t]{2}{*}{ True value } & & \multicolumn{4}{|c|}{ Sample size N } \\
\hline & & 150 & 300 & 450 & 600 \\
\hline & $\widehat{N V R}_{T}$ & & & & \\
\hline \multirow[t]{2}{*}{5} & Median & 3.27 & 3.98 & 4.55 & 4.51 \\
\hline & IQR & 4.26 & 3.09 & 2.73 & 2.82 \\
\hline \multirow[t]{2}{*}{1} & Median & 1.00 & 1.06 & 1.08 & 1.05 \\
\hline & IQR & 1.04 & 0.75 & 0.58 & 0.53 \\
\hline \multirow[t]{2}{*}{0.5} & Median & 0.57 & 0.57 & 0.55 & 0.54 \\
\hline & IQR & 0.62 & 0.41 & 0.33 & 0.30 \\
\hline \multirow[t]{3}{*}{0.1} & Median & 0.19 & 0.14 & 0.13 & 0.13 \\
\hline & IQR & 0.23 & 0.12 & 0.10 & 0.09 \\
\hline & $\sqrt{N V R_{S_{4}}}$ & & & & \\
\hline \multirow[t]{2}{*}{50} & Median & 30.88 & 39.56 & 44.84 & 44.04 \\
\hline & IQR & 37.60 & 34.08 & 29.70 & 29.72 \\
\hline \multirow[t]{2}{*}{10} & Median & 11.87 & 11.73 & 11.59 & 10.83 \\
\hline & IQR & 13.68 & 9.69 & 7.89 & 7.14 \\
\hline \multirow[t]{2}{*}{5} & Median & 8.19 & 6.94 & 6.81 & 6.11 \\
\hline & IQR & 10.40 & 5.87 & 4.92 & 4.77 \\
\hline \multirow[t]{3}{*}{1} & Median & 4.21 & 3.26 & 2.65 & 2.32 \\
\hline & IQR & 5.51 & 3.74 & 3.06 & 2.61 \\
\hline & $\widehat{N V R_{S_{2}}}$ & & & & \\
\hline \multirow[t]{2}{*}{50} & Median & 25.51 & 34.30 & 38.66 & 40.22 \\
\hline & IQR & 39.44 & 40.85 & 39.23 & 36.86 \\
\hline \multirow[t]{2}{*}{10} & Median & 9.64 & 9.49 & 10.18 & 9.57 \\
\hline & IQR & 12.56 & 9.97 & 8.79 & 7.61 \\
\hline \multirow[t]{2}{*}{5} & Median & 6.43 & 5.66 & 5.61 & 5.45 \\
\hline & IQR & 8.29 & 5.99 & 5.10 & 4.35 \\
\hline \multirow[t]{2}{*}{1} & Median & 2.89 & 2.17 & 2.05 & 1.78 \\
\hline & IQR & 4.03 & 2.80 & 2.34 & 1.83 \\
\hline
\end{tabular}

$\mathrm{N}$ is the sample size. IRQ means inter-quartile range $(N V R$ and statistics $\times 1000)$. I.e., " $N V R=5$ " means $N V R=0.005$, "median $=4.51 "$ means median $=0.00451$.

So, given the values of $\alpha_{j}, \beta_{j}$ y $\omega_{j}$, it is possible to calculate $\gamma$ and $\eta$. The constant $\lambda$ is

$$
\lambda=\frac{\alpha_{j} \beta_{j} \cos \left(2 \omega_{j}\right)}{\gamma_{j}^{\star} \eta_{j}^{\star}}
$$

where $\gamma_{j}^{\star}$ and $\eta_{j}^{\star}$ are the roots inside the unit circle (see Eq. (A.7)).

Combining Eqs. (A.2), (A.7), (A.11), and (A.12) we can write the equivalent ARMA model for the $s_{t}^{p_{j}}$ component as

$$
\varphi_{j}(L) s_{t}^{p_{j}}=\left(\sqrt{\frac{\alpha_{j} \beta_{j} \cos \left(2 \omega_{j}\right)}{\gamma_{j}^{\star} \eta_{j}^{\star}}}\right)\left(1-\theta_{j}^{1} L-\theta_{j}^{2} L^{2}\right) \xi_{j_{t-1}}, \quad\left\{\xi_{j t}\right\} \sim \text { w.n. } N\left(0, \sigma_{\xi_{j}}^{2}\right) .
$$


Corollary 3. The pseudo-covariance generating function of each cyclical or seasonal component $s_{t}^{p_{j}}$ is given by

$$
\Lambda_{s} p_{j}(z)=\left(\sigma_{j}^{2} \frac{\alpha_{j} \beta_{j} \cos \left(2 \omega_{j}\right)}{\gamma_{j}^{\star} \eta_{j}^{\star}}\right) \frac{\left[1-\theta_{j}^{1} z-\theta_{j}^{2} z^{2}\right]\left[1-\theta_{j}^{1} z^{-1}-\theta_{j}^{2} z^{-2}\right]}{\varphi_{j}(z) * \varphi_{j}\left(z^{-1}\right)} \longrightarrow,
$$

where $\theta_{j}^{1}, \theta_{j}^{2}, \gamma_{j}^{\star}, y \eta_{j}^{\star}$ are given in Eq. (A.7), and $\varphi_{j}(z)$ is provided by Eq. (A.2).

\section{References}

Akaike, H., 1980. Seasonal adjustment by a Bayesian modelling. J. Time Ser. Anal. 1 (1), 1-13.

Bell, W., 1984. Signal extraction for nonstationary time series. Ann. Statist. 12 (2), 646-664.

Box, G.E.P., Hillmer, S.C., Tiao, G.C., 1978. Analysis and modelling of seasonal time series. In: Zellner, A. (Ed.), Seasonal Analysis of Economic Time Series. U.S. Department of Commerce-Bureau of the Census, Washington, DC, pp. 309-334.

Bujosa, M., 2000. Contribuciones al método de regresión armónica dinámica: Desarrollos teóricos y nuevos algoritmos. Ph.D. Thesis, Dpto. de Análisis Económico, Economía Cuantitativa, Universidad Autónoma de Madrid.

Bujosa, A., Bujosa, M., García-Ferrer, A., 2002. A note on the pseudo-spectra and the pseudo-covariance generating functions of arma processes. Working Paper 0203, Instituto Complutense de Análisis Económico, Universidad Complutense de Madrid.

Burman, J., 1980. Seasonal adjustment by signal extraction. J. Roy. Statist. Soc. Ser. A 143, 321-337.

Casals, J., Jerez, M., Sotoca, S., 2000. Exact smoothing for stationary and non-stationary time series. Internat. J. Forecasting 16 (1), 59-69.

Casals, J., Jerez, M., Sotoca, S., 2002. An exact multivariate model-based structural decomposition. J. Amer. Statist. Assoc. 97 (458), $553-564$.

García-Ferrer, A., Bujosa-Brun, M., 2000. Forecasting OECD industrial turning points using unobserved components models with business survey data. Internat. J. Forecasting 16 (2), 207-227.

García-Ferrer, A., del Hoyo, J., Martín-Arroyo, A.S., 1997. Univariate forecasting comparisons: The case of the Spanish automobile industry. J. Forecasting 16, 1-17.

García-Ferrer, A., Queralt, R., 1998. Using long-, medium-, and short-term trends to forecast turning points in the business cycle: some international evidence. Studies Nonlinear Dynam. Econom. 3 (2), 79-105.

Gomez, V., Maravall, A., 1996a. New methods for quantitative analysis of short-term economic activity. In: Prat, A. (Ed.), Proceedings in Computational Statistics. Physica, Heidelberg, pp. 65-76.

Gomez, V., Maravall, A., 1996b. Programs TRAMO and SEATS, instructions for the user (beta version: September 1996). Working Paper 9628, Bank of Spain, Madrid.

Harvey, A.C., 1989. Forecasting, Structural Time Series Models and the Kalman Filter. Cambridge University Press, Cambridge.

Hillmer, S., Tiao, G., 1982. An ARIMA-model-based approach to seasonal adjustment. J. Amer. Statist. Assoc. 77, 63-70.

Jakeman, A., Young, P.C., 1984. Recursive filtering and the inversion of ill-posed causal problems. Util. Math. 35, 351-376.

Koopmans, S.J., Harvey, A.C., Doornik, J.A., Shephard, N., 1995. STAMP 5.0: Structural Time Series Analyser, Modeller and Predictor. Chapman \& Hall, London.

Lawson, C.L., Hanson, R.J., 1974. Solving Least Squares Problems. Prentice-Hall, Englewood Cliffs, NJ.

Maravall, A., 1993. Stochastic linear trends. J. Econom. 56, 5-37.

Maravall, A., 2006. An application of the tramo-seats automatic procedure; direct versus indirect adjustment. Comput. Statist. Data Anal. 50, 2167-2190.

Pollock, D.S.G., 2003. Recursive estimation in econometrics. Comput. Statist. Data Anal. 44, 37-75.

Pollock, D.S.G., 2006. Econometric methods of signal extraction. Computat. Statist. Data Anal. 50, 2268-2292.

West, M., Harrison, J., 1989. Bayesian Forecasting and Dynamic Models. Springer, New York.

Young, P.C., 1991. Comments on likelihood and cost as path integrals. J. Roy. Statist. Soc. Ser. B 53, 529-531.

Young, P.C., 1994. Time variable parameters and trend estimation in non-stationary economic time series. J. Forecasting 13, 179-210.

Young, P.C., 1999. Nonstationary time series analysis and forecasting. Progr. Environ. Sci. 1, 3-48.

Young, P.C., Ng, C.N., Armitage, P., 1988. A systems approach to recursive economic forecasting and seasonal adjustment. Comput. Math. Appl. 18, 481-501.

Young, P.C., Pedregal, D., 1999. Recursive and en-bloc approaches to signal extraction. J. Appl. Statist. 26 (1), $103-128$.

Young, P.C., Pedregal, D., Tych, W., 1999. Dynamic harmonic regression. J. Forecasting 18, 369-394. 